\title{
The space of innovation: interaction and communication in the work environment
}

\author{
A Penn, J Desyllas, L Vaughan \\ The Bartlett School of Graduate Studies, University College London, Gower Street, London \\ WC1E 6BT, England; e-mail: a.penn@ucl.ac.uk; j.desyllas@ucl.ac.uk; l.vaughan@ucl.ac.uk \\ Received 8 February 1998; in revised form 30 September 1998
}

\begin{abstract}
As the pace of organisational change accelerates and as new technologies demand more rapid responses from organisations to changing conditions in their business environment, buildings are being called on to play an active role in helping to generate new organisational structures and in facilitating individual communication. This raises questions not only of the nature of organisational structure and of how communication technologies will affect that, but also of the possible mechanisms by which spatial structure can affect patterns of interaction in the work organisation. In this paper we will review two recent research-led design projects in which space syntax techniques were used to help define the building brief for an organisation which depends for its market lead on its ability to innovate. Building on research into the design of research laboratories, we found that patterns of space use and movement generated by spatial configuration have a direct impact on the frequency of contact between workers in office-based organisations. The frequency of contact is shown in turn to have an impact on workrelated communications cited as 'useful' by questionnaire. These patterns are found to be 'system effects' in that they cannot be attributed to an individual worker's desk location but appear to result from the configuration of the whole system of spaces through which people move in their daily work, and have detectable effects on the mean 'usefulness' to others of all workers in a part of a building. The analysis suggests, however, that spatial integration alone may be insufficient to support flexible working and that spatial differentiation is necessary to provide the range of environments needed by different types of work activity.
\end{abstract}

\section{Introduction}

Work organisations are undergoing a period of rapid change. Driven partly by changes in technology, coupled to the globalisation of markets and business processes, and partly by changing lifestyles and aspirations of the workforce, the modern work organisation has begun to outstrip current theories of organisational structure, let alone theories of the design of work environments. The pace is being set, in other words, through the practice of organisational evolution and restructuring, driven by the constraints and opportunities of their changing business environment, rather than by organisation theory itself. The pace of change itself, however, generates a need for good predictive theory. If we are to restructure organisations to respond to an increasingly dynamic and uncertain future business environment, how should it be done? What kinds of spatial environment will best support them? What will be the impact of the new technologies?

All of these questions demand a better theoretical understanding of the way that organisations function and, in particular, of the way that they support innovation. It is possible to argue that, at present, management and design practice is ahead of theoretical development in this debate. A wide range of novel organisational forms are being tried, along with an equally wide range of architectural and technological approaches to the design of the work environment. In this paper we first review the recent history of approaches to innovation, including those that suggest the possible role spatial design might play in facilitating or inhibiting innovation. Next we review two recent researchled projects in which detailed studies were carried out of office environments. The first study of a recently privatised energy utility (company X) was carried out both before 
and after the company moved to new premises in which spatial analysis played a role in the design process. Some of the lessons learned during this process set the context for the second case study.

The second study is of an advertising company (company Y) currently located in a single office in Central London near the main media production area of Soho. This study was carried out as a part of the briefing process for a series of major changes to the agency's way of working and, in particular, the way that it 'spatialises' the work process. One aspect of these changes is a potential move to new premises, but the changes that are currently in progress are much more thorough than this, involving the whole allocation and use of the spatial and communications resources of the work environment to individual workers. We give a brief overview of the specific activities of the agency and then describe the study that was carried out and a series of its main findings in some detail. Finally, we draw some of the main theoretical findings together in a discussion of the relationship between the work organisation considered as a resource available to facilitate individual creativity, and the work environment considered as a facility whose function is to bring the maximum leverage to bear from the disposition of the organisation's resources - both human and environmental.

This research has now begun to find a place in the practice of organisational change by helping to develop spatial designs of the work environment to support innovation. However, we believe that its main contribution is theoretical in that findings are tabled, for the first time so far as we are aware, suggesting possible detailed mechanisms through which the spatial design of the work environment might be implicated in 'innovation' per se.

\section{The organisation of innovation}

A recognition of the importance of innovation developed during the immediate postwar period, as economists tried to rationalise the massive growth of the German and Japanese economies and the relative stagnation of other nations. The response in management circles at the time relied mainly on the 'peace dividend' of operational research to generate a rational means, in Michael Shanks's words, for "reducing the chaos and complexity of business operations ... the 'creative fog' of management decision-to the simplicity of the laboratory or the control panel" (Shanks, 1967, page 50). Innovation and the management of innovation were largely seen as goaloriented processes in which strategic management and planning should play a critical role. The task of management was essentially one of deciding on goals and then planning the provision of resources-human, physical, and informational-to reach those goals.

In the thirty years that have elapsed since S Beer's publication of the main text in operational research (Beer, 1966), a whole range of 'scientific' management techniques have been tested and found wanting as ways of accelerating innovation. Although management techniques, broadly based on operational research and logistics, have had notable successes in increasing the efficiency of process-based industries and in certain aspects of project management, they have been found somewhat less successful when it comes to innovation in research and development (R\&D) and the creative or knowledge-based industries. In these industries, somewhat 'softer' strategies began to be developed during the late 1960s and 1970s involving 'brainstorming' and formal 'networking'. However, an investigation by Tom Allen of information sources critical to the successful outcome of defence-related engineering R\&D projects in the USA raised doubts as to their effectiveness (Allen, 1977). This research found that information and ideas critical to successful innovations seldom came either from brainstorming or from larger scale networking. In the case of the former, the brainstorming group 
was at best selected on the basis of a current view of the problem at hand and tended to encapsulate a particular viewpoint. In the case of the latter, actual contact tended to be too infrequent to provide the critical information or stimulus at the precise time when it was needed. This research did produce evidence, however, that the critical information leading to genuine innovations came from outside the immediate work group but from within the organisation. Allen surmised that "the inner team cannot sustain itself without constantly importing new information from the outside world ... such information is best obtained from colleagues within the organisation" (Allen, 1977, page 123).

Hopes are now being placed in organisational structures or procedures such as 'total quality management' and 'reinvention' to offer increased performance in these areas of work. So far as procedural devices are concerned, the predominant moves have been to minimise fixed reporting structures and to develop strategies to increase individual responsibility in their place. There is a growing perception that innovations tend to come from the grass roots. 'Managers' are being replaced by 'facilitators', and staff are being trained in 'self management'. The focus is on the development of a 'corporate culture' conducive to the aims of an organisation, rather than on enforcing organisational aims through a management hierarchy and formal mechanisms.

In terms of organisational structures, the once fashionable matrix organisation has already given way to the project team, and the low-hierarchy organisational form. The fashion is currently turning to the network or ' $\mathrm{N}$-form' organisation and 'virtual companies' as structures which make use of the new communications technologies to allow rapid response to a changing business environment. However, each of these is essentially an organisational form proposed in isolation from the particular nature of an organisation's work process, the effects of the spatial organisation of work, and the design of its workplace. Still it seems that the realisation of new organisational forms, and in particular their spatial realisation, is being driven by practice rather than theory.

One of the reasons for this, we believe, is that with few exceptions there has been little in the way of formal research into the effects of the desigrt of the workplace on the performance of creative or innovative organisations. Recent research in which space syntax was used to investigate work environments in research laboratories has found evidence that the pattern of space in building interiors affects patterns of 'useful' interactions between research groups (Hillier et al, 1990; Hillier and Penn, 1991; Penn and Hillier, 1992). The main finding of this research was that the mean integration of an area of a building, say a floor or a wing, was related to the mean degree to which staff located in that area were found 'useful in their work' by people from other research groups. The more integrated the part of the building, the more useful people were found outside their immediate group. This finding also held at the level of whole buildings and organisations (figure 1) and suggests that spatial layout could

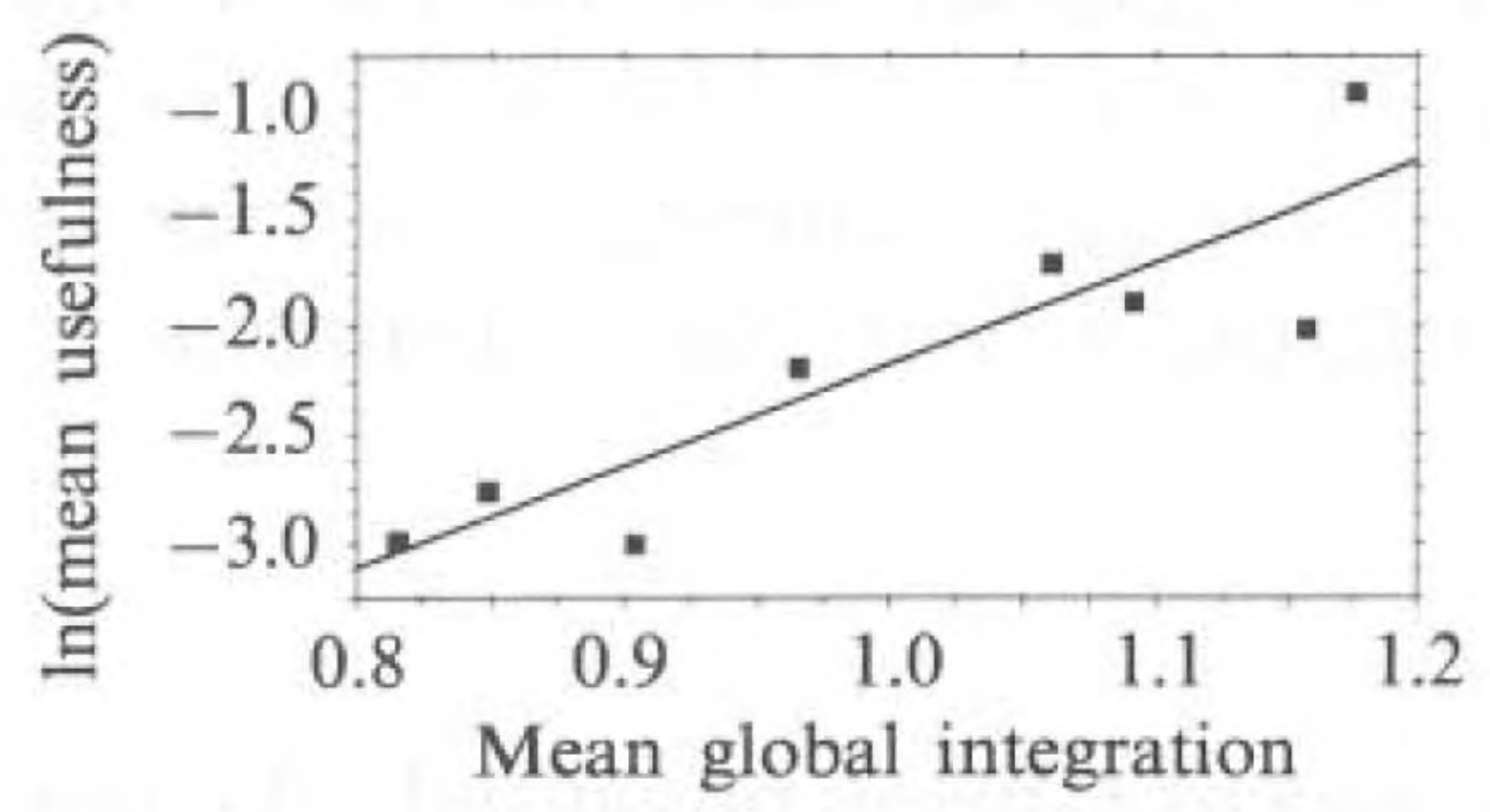

Figure 1. The correlation of the mean integration value for each whole building with the natural logarithm of mean useful contact rates for the seven original buildings in the sample as reported in Penn and Hillier (1992), but including an eighth laboratory studied more recently using the same methodology, $r=0.891, p<0.001$. 
play a key role in facilitating - or inhibiting - the effective use of human resources in innovation-based organisations.

The mechanism suggested by these findings was that spatial patterns affect movement patterns and that movement patterns bring people past other people's workstations. In the case of research laboratories this contention was supported by an analysis of the relationship between patterns of local movement within a research group area, global movement around the building as a whole, and the location of interaction within the laboratory. Local 'within lab' movement and local conservation groups were closely related but under different spatial configurations these focuses of interaction were either brought into proximity with or were separated from movement around the building as a whole (Hillier and Penn, 1991; Penn and Hillier, 1992).

Research carried out by Hillier et al (Grajewski, 1992; Hillier and Grajewski, 1987) found occupation density and mean spatial integration to be the two main factors determining observed levels of interaction in office environments. The same study also found that people in more segregated locations within the work environment move more than those in more integrated locations.

Related research in which video was used to capture the precise way in which interactions arise in the workplace (Backhouse and Drew, 1992) suggested that a mechanism of 'recruitment' of passers-by into conversation could account for the impact of global spatial structure on interaction patterns. This research found that over $80 \%$ of observed work-related conversations took place in a manner that was unplanned. By observing the microstructure of nonconversational behaviours, the researchers found that those involved in concentrated work at the workstation were generally held to be 'unavailable' for casual conversations. However, as soon as an individual got up from his or her desk to go somewhere else in the office, he or she was considered to be 'available' for interaction and would be 'recruited' into conversation by those who were passed. Because a person sitting at a workstation could never tell when a particular individual would walk past, the interaction was essentially unplannable. This mechanism could be held to account for the differences in mean 'usefulness' at the level of whole populations in different building layouts through the effect of larger scale configuration and local visibility in bringing moving, and potentially 'available', people into the field of view of those at the workstation.

These findings give rise to a simple theory of how building design might in principle be held to relate to organisational function through the construction of the 'local to global' interface. In particular, the pattern of useful work-related interaction between groups, which Allen had found to be critical to innovation, appears to rely on this interface. Two more recent practical studies have shown that these findings also hold for more general office organisations. However, these studies and their associated design projects have also suggested that a simple maximisation of integration and visibility may be inadequate to deal with the reality of organisational function in the work environment. We shall suggest that the pursuit of spatial integration to the exclusion of all else can lead to a 'homogenisation' of space, resulting in a lack of group identity, or possibly resulting in behaviours, including spatial rearrangements, to the disbenefit of the local to global interface.

\section{Company $X$ and its two sites}

Company $\mathrm{X}$ is a national energy utility which has recently been privatised. As one aspect of its strategy is to create a new corporate culture, the company decided to build a new operational headquarters to replace its existing premises. In order to advise on the design of the new headquarters building, a detailed study of the existing premises 
was carried out, and on the basis of this the early design strategy was modelled and advice given on spatial strategies to help achieve the main aims of the new corporation.

The existing headquarters building was composed of four building blocks linked into a single complex by means of a corridor system and bridges at first floor level. Three of the blocks were two-storey linear or square blocks, but the fourth was a sevenstorey tower (figure 2). The spatial structure of the building was highly segregating at a global level, with individual business units generally occupying well-defined floors or parts of floors within single blocks. Business units were thus radically separated from each other. Spatial analysis, observations of space use, and a questionnaire survey to determine patterns of interaction between business units were carried out.

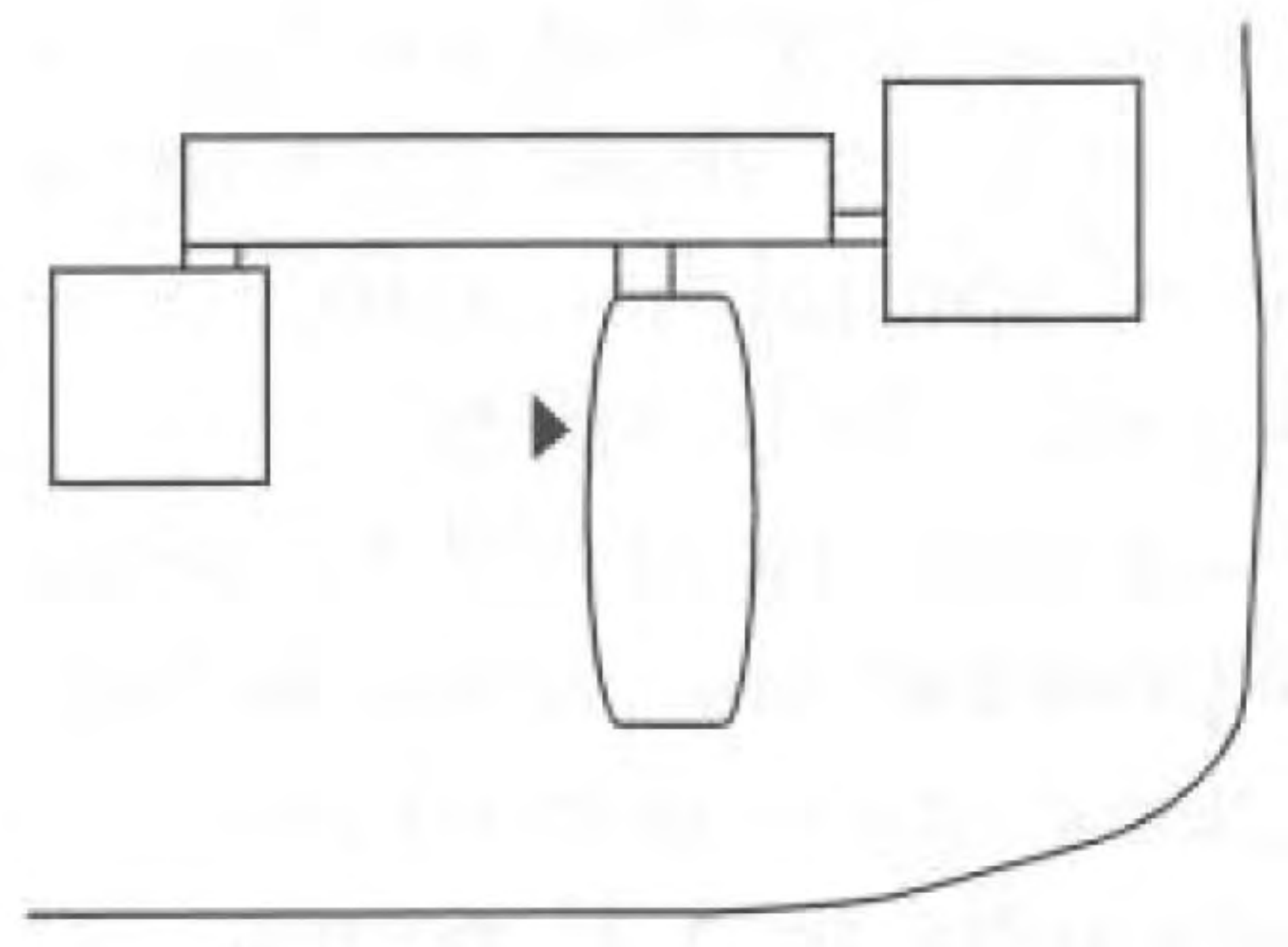

Figure 2. Schematic site plan for company $\mathrm{X}$ original headquarters buildings, comprising three low blocks and a tower all linked at first floor level. The arrow indicates the entrance.

In the questionnaire survey three staff members from each business unit were asked to report on the frequency with which they encountered staff from each of the other business units and the frequency with which they passed through each of the other business-unit work areas. These data were then analysed to assess the degree to which the spatial structure of the site could be held to have an effect, first, on the way that people moved around the buildings during their everyday work, and, second, whether there were any detectable effects on reported interaction and encounter between business units. The main aim was to see whether staff located in spatially isolated units were cited as being less frequently encountered by those from other units and whether frequency of encounter could be forecasted from an analysis of the spatial pattern of the building design alone.

The results of the study were conclusive. When business units in which over $25 \%$ of desks were unoccupied were excluded, there was a significant positive correlation between spatial accessibility and the mean frequency with which encounter was cited by other business units (figure 3 ). It was clear that encounter and interaction between units was being affected by the spatial isolation inherent in the building layout. Although we were unable to bring direct evidence to show that this then had an impact on levels of interaction and innovation in the specific case of company $\mathrm{X}$, reference to the previous laboratory studies suggested that 'useful' work-related interaction between

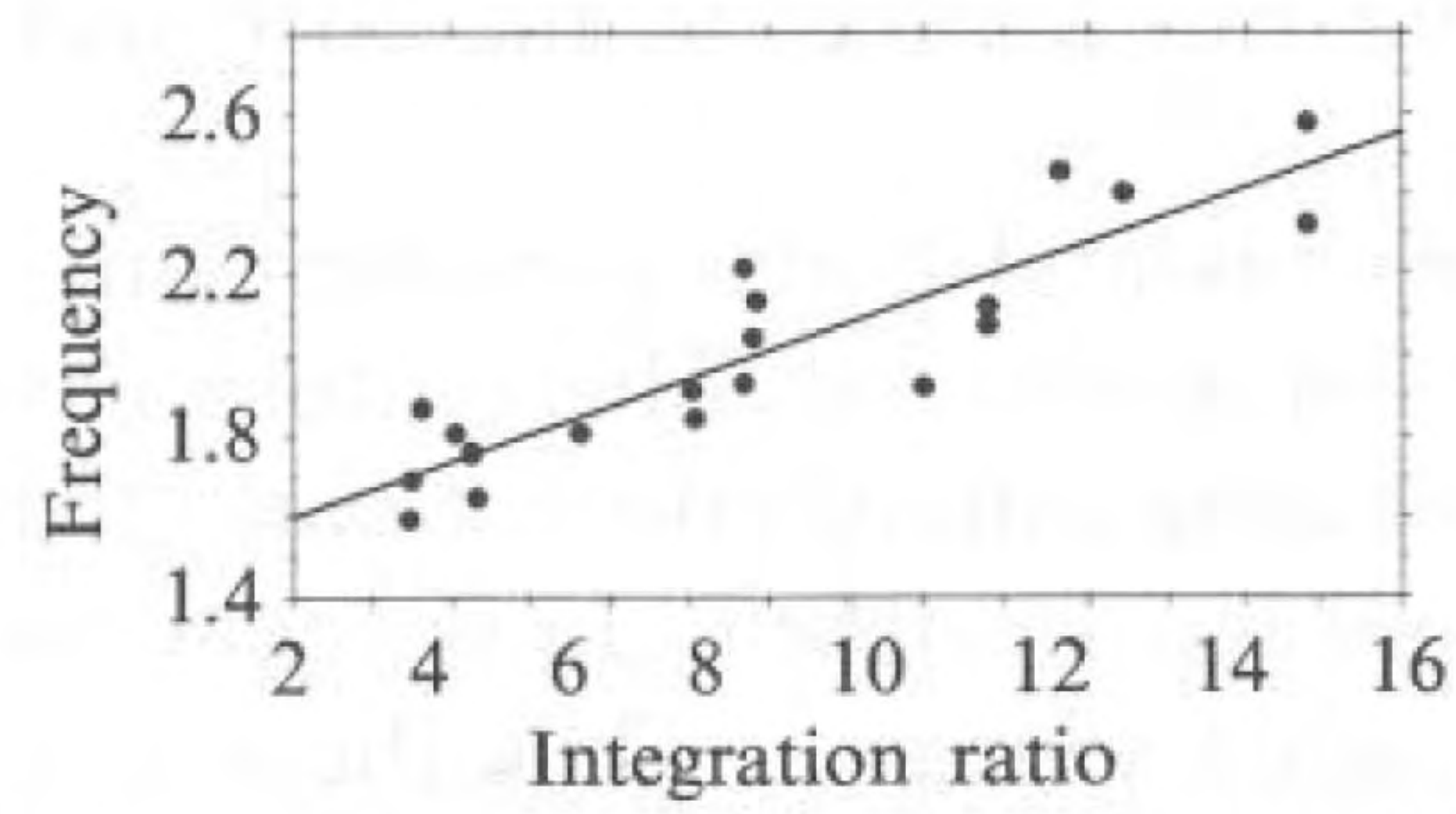

Figure 3. The correlation of stated frequency of encounter between business units and the mean ratio of local to global integration for their area, $r=0.898, p<0.0001$. 
members of different units was likely to be affected. This was felt to be critical to the success of a company that had moved from being a public-sector utility in a monopoly position to a competitive private-sector corporation. It would be critical to the success of the company that new market opportunities and innovations be developed and exploited and that the 'overheads' of the headquarters be reduced to a minimum. For both of these reasons high levels of interaction between business units were felt to be desirable.

On the basis of these findings we were then asked to analyse the proposed building design for the new headquarters building and to suggest ways in which its layout might be modified to enhance interaction and communication between business units. The main effects of that advice on the design were to bring the main circulation routes directly adjacent to the street on either side of the building and to equalise the size of the floor plate on either side and on each floor. It was possible to show that these design changes would have a significant effect on the degree of spatial accessibility of each area in the building and could in principle eliminate isolated 'cold spots'.

Some eighteen months after the building was occupied we then returned to carry out a postoccupancy evaluation. This repeated as nearly as possible the methodology used in the previous site. Two clear differences emerge from the comparison of the two buildings: the density of the organisation has increased significantly to 5.97 people per $100 \mathrm{~m}^{2}$ compared with 4.68 on the previous site, an increase in observed density of nearly $28 \%$. In particular, the number of people observed to be seated as opposed to standing or moving has increased substantially from $69 \%$ of all those observed to $80 \%$, with levels of movement dropping substantially to just $5 \%$ from $11 \%$. The number of people observed to be talking has remained almost precisely the same at $36 \%$.

However, according to the respondents to the questionnaire, the frequency with which other departments in the organisation are 'visited' has increased by $9 \%$ from 2.08 to 2.27 on a 1 to 5 scale from never to daily. Meetings at the new building are much more 'unplanned' than in the previous building, with $25 \%$ of meetings between business units reported as unplanned and only $11 \%$ reported as planned. Meetings also took place less at workstations in the new building (Own Desk meetings dropped from $38 \%$ of responses to $21 \%$, Other Person's Desk meetings from $50 \%$ to $34 \%$ ).

Movement is lowest inside the work bays and higher on the corridors, with peak levels on the bridges that link across the atrium to the stairs. This pattern is depicted graphically in figures 4(a), 4(b), and 4(c), which show the routes taken by different kinds of trip by using movement trails. The highest level of movement is in the middle stairwell bridge ( 131 people per hour). This reflects the importance of the stairs in the global pattern of movement from floor to floor. Figure 4(a) shows global 'through movement' predominantly on the corridors and bridges, whereas figure 4(b) shows the trails of trips that had either an origin or a destination within the observation area. These take routes linking the work bays to the main corridors. Figure 4(c) shows the trails for local 'within area' trips. These are predominantly in the internal routes within departmental areas, and most commonly the links that run parallel to the corridors but are deeper within the bay.

The main corridors have very little internal movement and carry predominantly through movement with a large proportion of to and from movement. This pattern has two important consequences. 'Strangers' who are just passing through do not enter the department spaces without a specific person to visit, and local workers do not tend to use the public corridors for a large proportion of internal journeys. Thus there is a separation of localised movement from globalised movement. Where mixing does take place is on the entry lines from the corridor to the work bays. However, this separation is apparently not perceived as such by the building users. The mean frequency cited by 


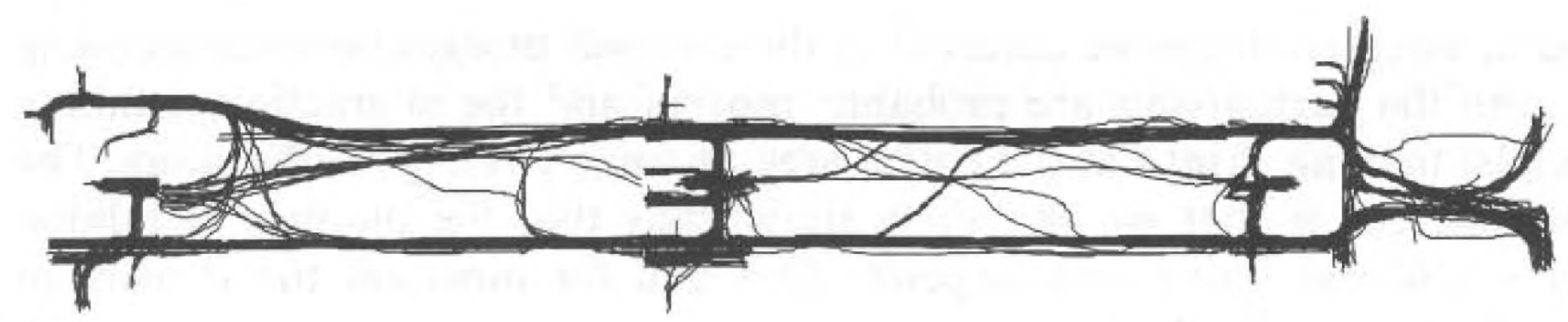

(a)

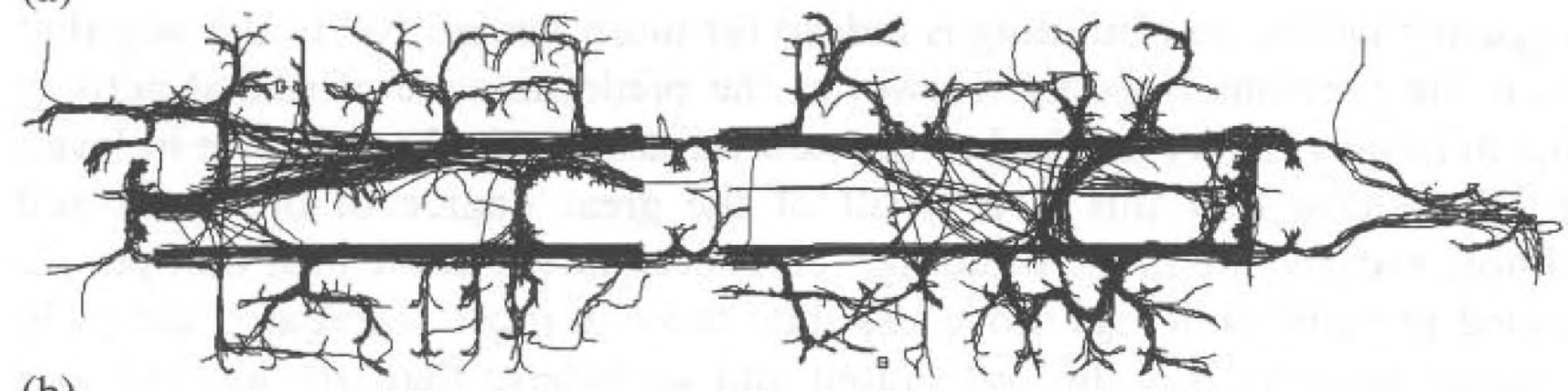

(b)
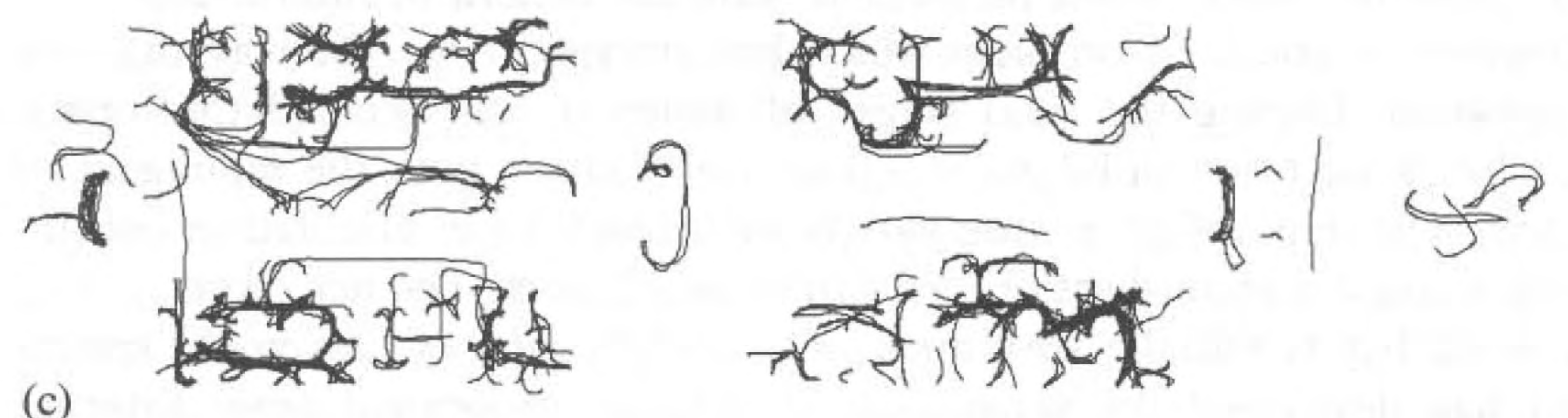

Figure 4. Pattern of movement of company $X$ : (a) through movement; (b) movement to and from desk locations within the observation area; (c) local movement within the observation area.

questionnaire respondents for passing through other business units is $9 \%$ higher than in the previous premises. This may be on account of the high degree of visual openness in the floor layout, and of the use of low screens and storage units within work bays.

Figure 5 shows that interaction (circles around talking groups) can be seen to take place in a number of different kinds of location and can be divided into formal planned meetings and informal unplanned interactions.

Inside the cellular formal meeting rooms there is interaction where all participants are seated and a meeting is taking place. Some areas of the open plan also contain meeting tables with many seated people that exhibit similar patterns of use. In the open-plan work areas single seated workers do not tend to interact with each other, reflecting the fact that they are getting on with work. However, there is interaction between seated and standing people, reflecting a visitor at a person's desk is in interaction with him or her.

In the corridors there is quite a lot of interaction taking place between standing people and the seated people just inside the work bays. This is apparently unplanned interaction between passing people and the most visible people seated near the corridor.

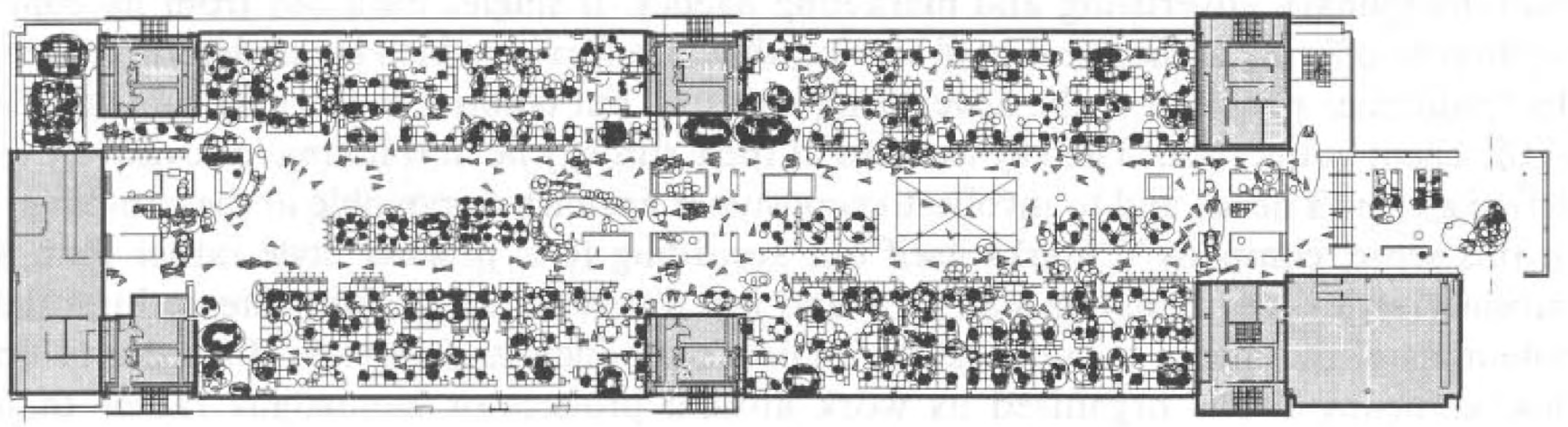

Figure 5. Static space use and interaction of company X. The black dots represent seated people, open dots standing people, and the circles are drawn around talking groups. 
A further kind of interaction can be detected in the stairwell bridges between standing people. Here both the participants are probably 'movers' and the interaction is taking place either whilst making drinks at the coffee area or while passing on the stairs. The result of these patterns is that we can show statistically that the number of talking people within a business unit's area depends first and foremost on the density of movement within the area (table 1).

All this suggests that the new building is indeed far more 'generative' in the way that it functions than the previous building. However, the predominance of seated activity relative to other activities is very marked at the new building as is the decrease in levels of movement. We believe that this is a result of the great degree of openness and accessibility almost everywhere in the building. It has been noted in the past that people in more integrated parts of buildings move less than those in more segregated areas. In this case, the entire building is highly integrated and we believe that this has led to a reduced need to leave the workstation in order to gain the benefit of interaction.

There is, however, a potential problem which has emerged from the way that the building was designed. During the final stages of design it was decided that space planning should be carried out 'in-house' in direct consultation with the managers of each business unit. This has led to a wide variety of detailed local circulation configurations all using a single standard set of furnishings and fittings. The net result is that, although every work bay is visually very open, the configuration of movement spaces within the bays has developed the separation of through movement from internal movement shown in the movement trails of figure 4 . There appears to be a natural tendency, in the face of a high degree of global integration, for business-unit managers to configure their space to allow for internal movement away from the global movement structure. We believe that this may be a response to a perceived need to create and reproduce the local group identity, which is threatened by the larger scale structure of both the building and the organisation.

Table 1. Multiple regression of numbers of observed talking people per business unit with the metric density of different types of activity. Density of movement is the most significant variable.

\begin{tabular}{lcl}
\hline Variable & $t$-value & Probability \\
\hline sitting/area & 1.076 & 0.2882 \\
standing/area & 1.066 & 0.2926 \\
moving/area & 2.557 & 0.0145 \\
$r=0.519, \quad p=0.0053$ & \\
\hline
\end{tabular}

\section{Company $\mathrm{Y}$ and the $\mathrm{K}$ house premises}

A second case study has allowed us to investigate these factors further. Company $\mathrm{Y}$ is a multidisciplinary advertising and marketing agency. It singles itself out from its competition by offering a 'client-centred' service, that is, a service which is not determined by the traditional structure of the advertising industry, but tailored to the particular needs of the client in question. The key features of their strategy lie in thinking innovatively to define a client's needs and to involve the consumer as much as possible in the campaign. In this sense, company Y marks itself out according to a 'process' style rather than a 'product' style - the campaigns all look and feel different, but all innovate and use the potentials of the media to promote their client's products and services. In order to do this, company $\mathrm{Y}$ has organised its work around projects or campaigns rather than according to professional disciplines and brings together an appropriate team of disciplines for a client's specific needs. It calls this approach '3-dimensional marketing'. 
Company $\mathrm{Y}$ is also distinctive in that it has explicitly developed ways of trying to maximise innovation and the degree of random communication between staff on which it believes that the 3-dimensional marketing concept depends. People are assigned desk locations more or less randomly. Neither departments representing the traditional disciplines in the profession, nor projects or campaigns are assigned specific spatial areas in the office. The departments and projects come together in programmed meetings but the spatial location of individuals is used to randomise and bring people in contact with people working on other projects or from other disciplines. The use of space to randomise contacts is reinforced by a 'six-monthly move' in which most people are 'shuffled' and move to new desk locations. This serves three main purposes: people sit next to new people and so develop different sets of contacts; nobody is assigned to a poor location forever; and it helps to eliminate clutter. There are also other 'shuffling mechanisms' in operation, such as a ban on internal telephone calls and memoranda. If you want to speak you get up and move through the office. Conversations are face to face, and the walk takes you past other people and increases the chance of opportunistic meetings.

This concentration on maximising random interaction is to the best of our knowledge unique. Most other organisations assign areas of their offices either to disciplinary groups or to project teams and use spatial correspondence to help reproduce some part of the organisational structure. The decision to spatialise neither is novel and this means that any reproduction of organisational structures must rely largely on 'transpatial' means such as monthly group meetings. This clearly places an onus on the generation of new organisational and social forms rather than on their conservation and makes any reproduction more explicit and so open to view and criticism.

Company $\mathrm{Y}$ has grown since it was first set up eight years ago. Initially it occupied only two thirds of the fifth floor of $\mathrm{K}$ house, then it took on the remaining third, and finally it took on one third of the fourth floor. The fifth-floor office area is relatively simple in design conception and makes effective use of interior layout to overcome one of the main problems of the design of $\mathrm{K}$ house. $\mathrm{K}$ house is arranged as a square footprint with central stairs and lifts, light well, toilets, and escape stairs. The remaining usable space makes a 'horseshoe' which is entered from the stairs and lift on one side. This building plan effectively separates the three sides of the horseshoe from each other. The interior layout on the fifth floor makes use of a curving red wall to enclose a set of meeting rooms on the light-well side of the corridor and at the same time to help eliminate the boundary between the three segments of the horseshoe-as you move around the corridor you always have a red wall on your left, and because the wall is curved, the view opens up ahead continuously, rather than as a series of sudden transitions that would have resulted from straight walls and corners. The effect is subtle and tends to unify or 'straighten' the corridor, at least perceptually. It can be argued that in unifying the space of the fifth floor the effect is also to lose a sense of orientation and to homogenise space-all parts of the fifth floor tend to feel similar rather than offer a range of different environments.

The fourth floor feels quite different. It has nowhere near the same feeling of activity and liveliness as the fifth floor. The interior fit-out has been designed with almost precisely the opposite intentions to the fifth floor. Instead of homogenising and unifying space, the designers have sought to provide a range of different kinds of space and to use the built fabric and decor to distinguish between them. A strong distinction is made between circulation space and workstation areas which are divided from each other by a silver galvanised metal screen wall. We understand that from its initial occupation it was clear that the fourth and fifth floors did not work well together. 


\section{Visible patterns of space use}

Figure 6 shows the location of all activities over all observations. A number of key features are visible. Movement on both floors is concentrated along the corridor spaces. Movement on the fifth floor is strongest along the corridor and especially the middle of the corridor along the top of the horseshoe. It branches off into the bays of desks and falls off as it gets deeper into the bays towards the external wall. Movement on the fourth floor is also concentrated on the corridors but there is a secondary internal corridor along the external wall which gathers a fair amount of movement.

Sitting is concentrated in the lowest movement spaces and on the periphery of the building on the fifth floor but also in the central desk area of the fourth. On the fifth floor, standing is concentrated in the places along the side of the corridor just off the main movement flow. There are also some (but fewer) standing people next to desk locations on the periphery and in the creatives' offices, but almost no standing in the meeting rooms. The result is that standing on the fifth floor prioritises the spaces that link between movement and sitting (that is, the entrances to the bays just off the main movement line). Standing on the fourth floor seems only to be concentrated inside the desk areas themselves, at the photocopier and in the kitchen.

Talking in the building is divided between talking in meeting rooms (where everybody sits and the meeting is programmed) and talking that takes place where sitting and standing, or standing, groups of people are in contact. This appears to be a more casual and unplanned form of contact. On the fifth floor there is quite a lot of talking between standing people themselves just off the main movement flows where they are still close to the movement flow but just out of the way to avoid being trampled on. Talking on the fourth floor is concentrated only in meeting rooms or cellular offices and is very predominantly between seated people.
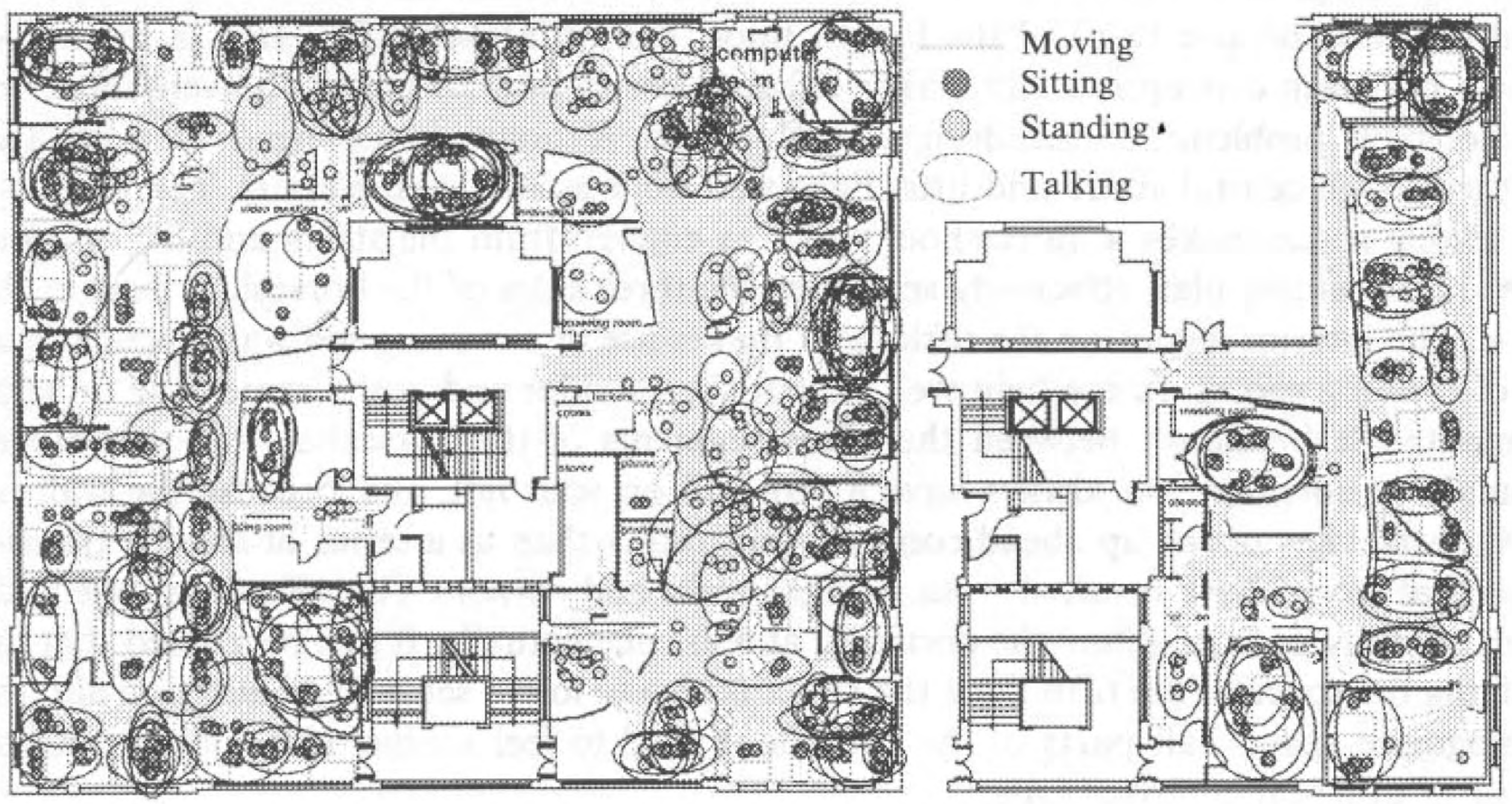

Figure 6. Observed patterns of space use and movement in company Y.

\section{Activity ratios}

The ratio of standing people to sitting people is of interest because those standing tend to be visiting other people (either in a planned visit to a seated person or an unplanned stop to chat with someone) whereas those sitting tend to be inhabiting a space. The ratio of standing to sitting people can thus be seen as a measure of the amount of visiting which is taking place in an area. 
The 'visiting' ratio varies radically between the fifth floor and the fourth floors as shown in table 2 , which also gives the mean count per round for sitting and standing people on each floor.

This shows that there are almost double the number of sitting people to standing people on the fourth floor compared to the fifth. This difference is not really explicable in terms of the smaller size of the fourth floor because this should lead to a lower number of both types of activity and not necessarily to a lower ratio. If we look at the ratio of desk spaces available on each floor to the observed sitting people per round (table 3), we find that even in terms of seated activity the fourth floor is less densely occupied than the fifth.

Taken together with the visiting ratio, this suggests that the occupants of the fourth floor spend more of their time away from their desks than those on the fifth, and are visited less. Although there is obviously a certain amount of visiting within a floor (for example, where a person on the fourth is visiting another on the same floor), the overall ratio is still dramatically different.

Table 2. The ratio of standing to sitting people, or the 'visiting' ratio.

\begin{tabular}{llll}
\hline & $\begin{array}{l}\text { Standing people } \\
\text { per round }\end{array}$ & $\begin{array}{l}\text { Sitting people } \\
\text { per round }\end{array}$ & Visiting ratio \\
\hline Fifth floor & 10.45 & 39.05 & 0.27 \\
Fourth floor & 1.50 & 10.15 & 0.15 \\
& & & \\
\hline
\end{tabular}

Table 3. Available desks per seated person per observation round.

$\begin{array}{ll}\text { Desks } & \begin{array}{l}\text { Sitting people Desks per sitter } \\ \text { per round }\end{array}\end{array}$

\begin{tabular}{llll}
\hline Fifth floor & 86 & 39.05 & 2.2 \\
Fourth floor & 26 & 10.15 & 2.6
\end{tabular}

\section{Spatial analysis of $\mathrm{K}$ house}

The maps in figure 7 (see over) are 'all-line' axial maps. These represent all the possible longest lines of movement on each floor (each floor is considered separately here), with furniture regarded as a barrier to movement. The grey scale of each line represents its degree of integration. The striking similarities of the maps in figure 7 to the pattern of movement observed in figure 6 points to a fundamental relationship between the structure of space and movement. The number of lines along the corridor spaces is much greater than in dead ends (as in the movement map), and the most integrated area of the axial map along the top of the horseshoe is also the area where the peak of movement occurs.

The effect is more systematic than this. A series of notional 'gates' on the fifth floor were selected as measurement points at which to compare the total number of moving people who passed and the number and degree of integration of axial lines in the all-line model in figure 7. As can be seen in figure 8 (see over), there is a strong relationship between the movement observed on the fifth floor and the mean integration value of the lines that cross that 'gate'. However, there are some places in the axial map where the model shows strong integration but the movement falls off, particularly at the end of corridors. This is demonstrated statistically in figure 8 , which shows a clear split in the relationship of movement to the average integration of passing lines. 

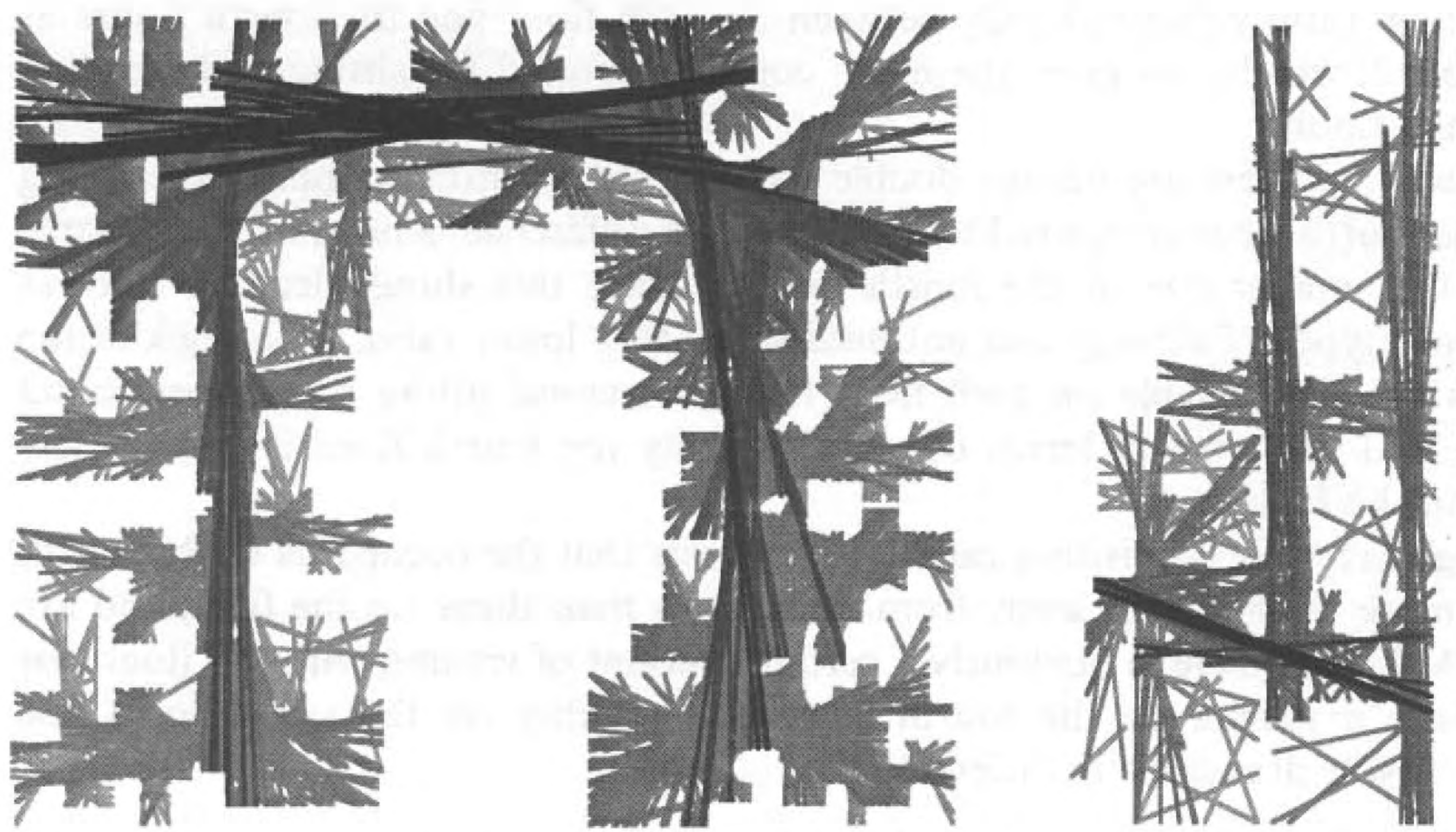

Figure 7. Global integration in the all-line map for the two floors of company Y.

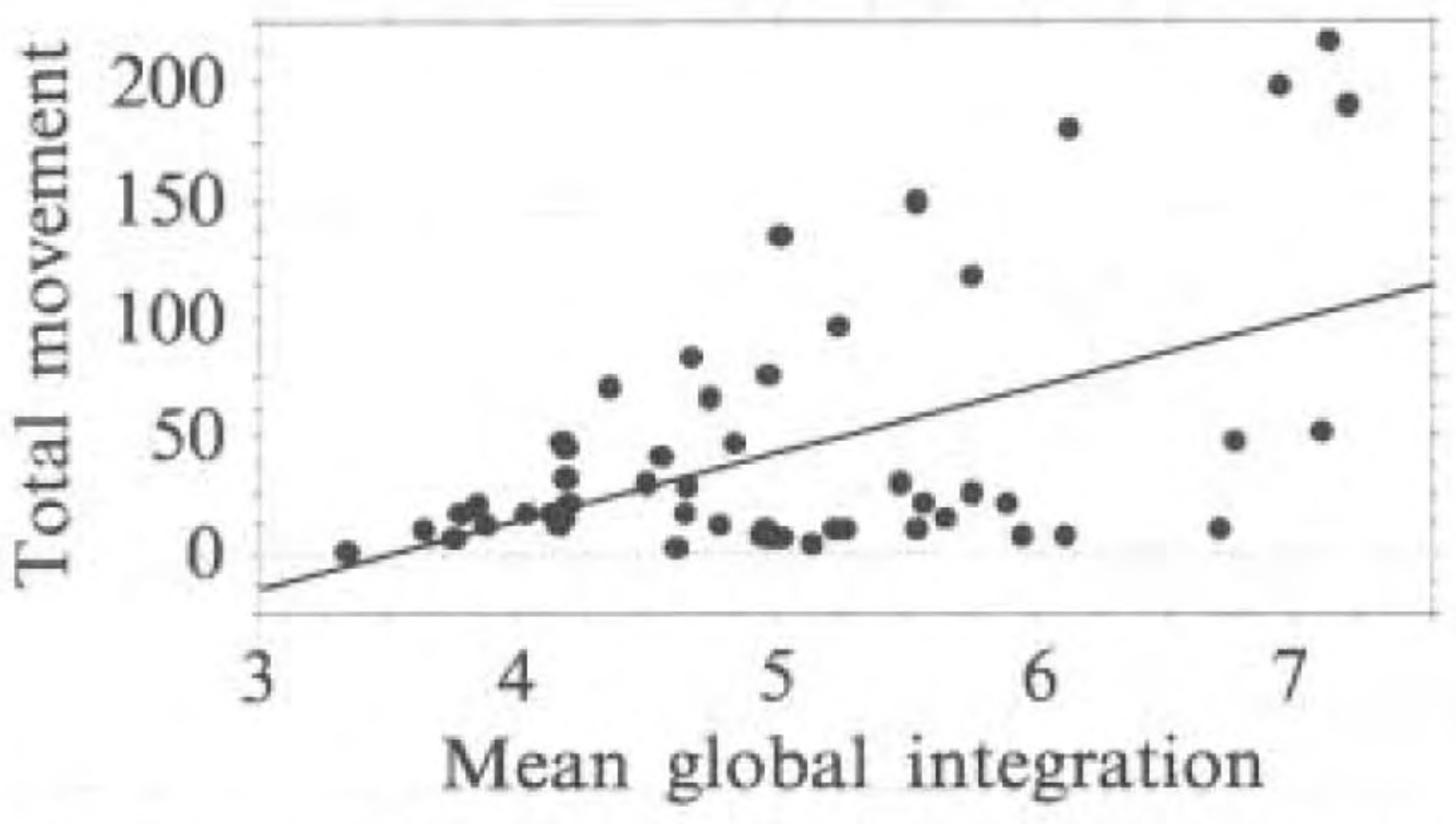

Figure 8. Movement observed and mean integration value of lines passing through a gate, $r=0.502, p=0.0001$.

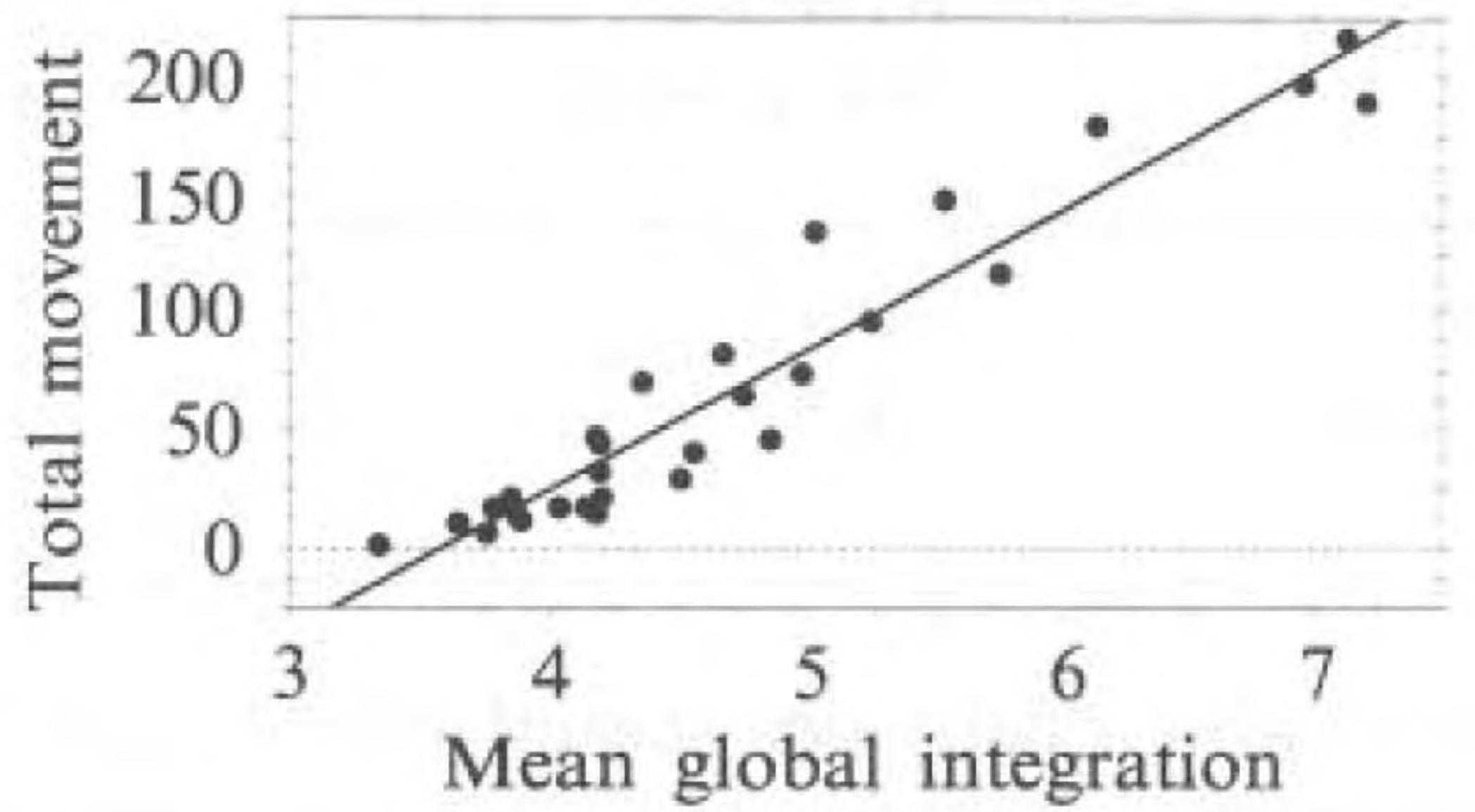

Figure 9. Movement observed and mean integration value of lines passing through a gate, excluding gates to dead-end spaces, $r=0.959, p=0.0001$.

The gate locations on the bottom leg of the scatter are those on the entrance to dead-end spaces where integrated axial lines penetrate but movement falls off because there is nowhere else to go. By exclusion of these dead-end gates, a very clear relationship is produced (figure 9). This is possibly a first demonstration of the ability of the all-line map to account for differences in movement rates segment by segment along the length of an axial alignment. The correlation is also considerably stronger at $r=0.959$ than that found by using the fewest line map $(r=0.72)$.

These findings point to a number of fundamental relationships. The structure of space has been shown to play an important role in structuring the pattern of movement. Axial lines are important in the structure of space because they link spaces together linearly and in this sense an axial line represents a possible movement route. The way that those movement routes are used by people results in the middle of the line being more heavily used than the end because there are fewer possible routes that take you through the ends. Another important factor in the spatial structure of the building is the relationship of the internal spaces to the entrance in terms of changes of direction, or steps of depth in the axial map.

As we can see in figure 6, people tend to sit 'deep' from the entrance in terms of the structure of movement lines. Figure 10(a) shows how the average number of seated people along any axial line tends to increase with depth from the entrance. The opposite is the case for standing people; they tend to be 'shallower' to the entrance than seated people and their numbers decrease with depth [figure 10(b)]. Talking people rise in numbers to a maximum at three steps of depth and then tail off again [figure 10(c)]. 


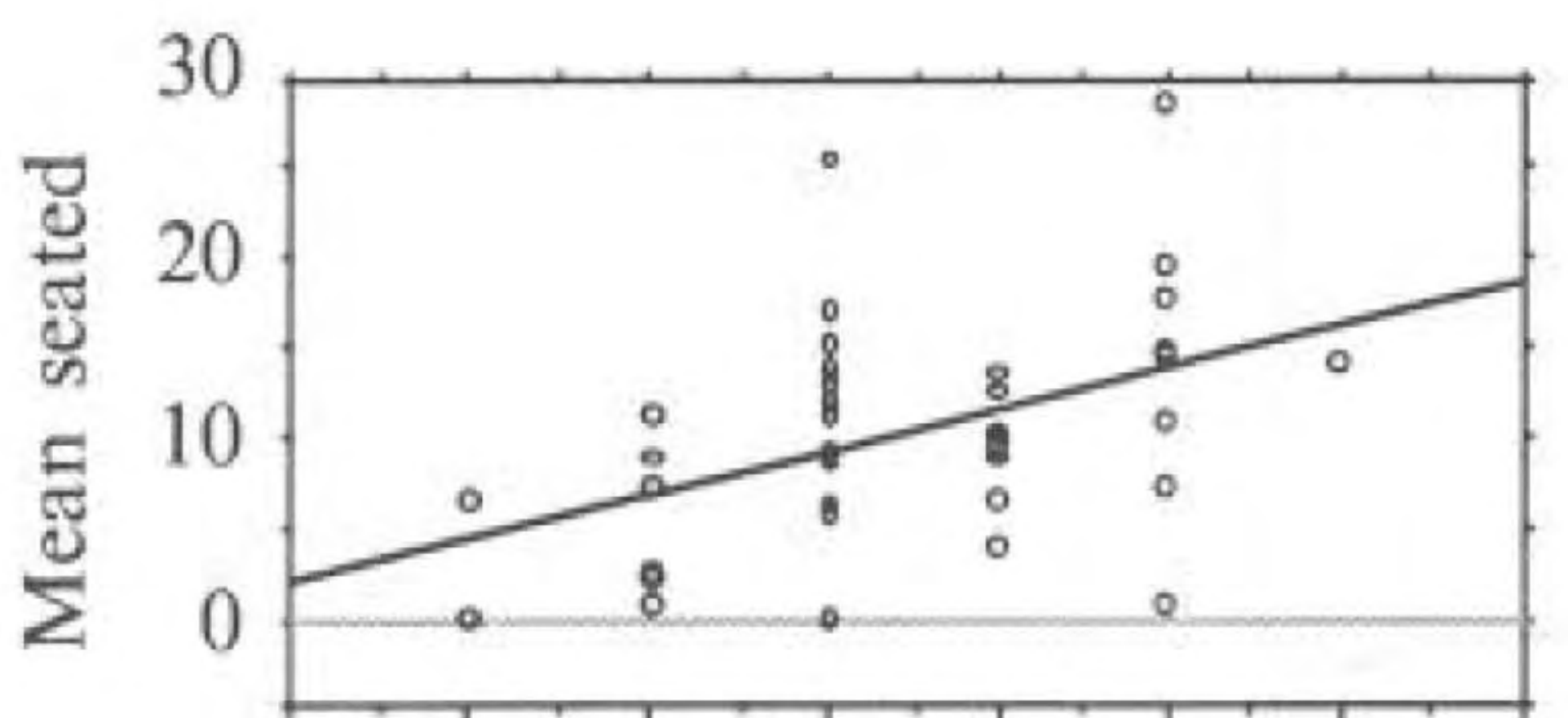

(a)

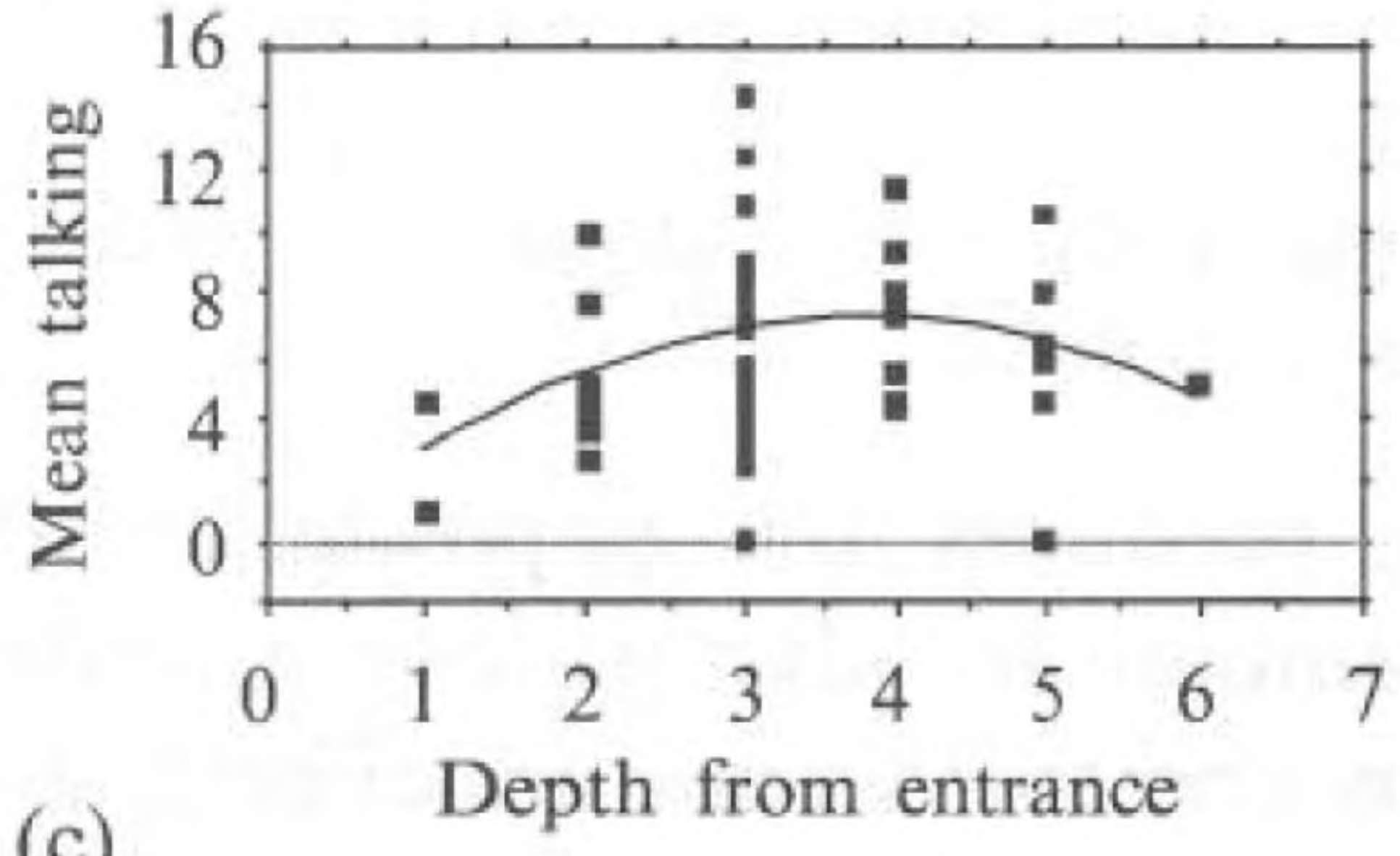

(c)

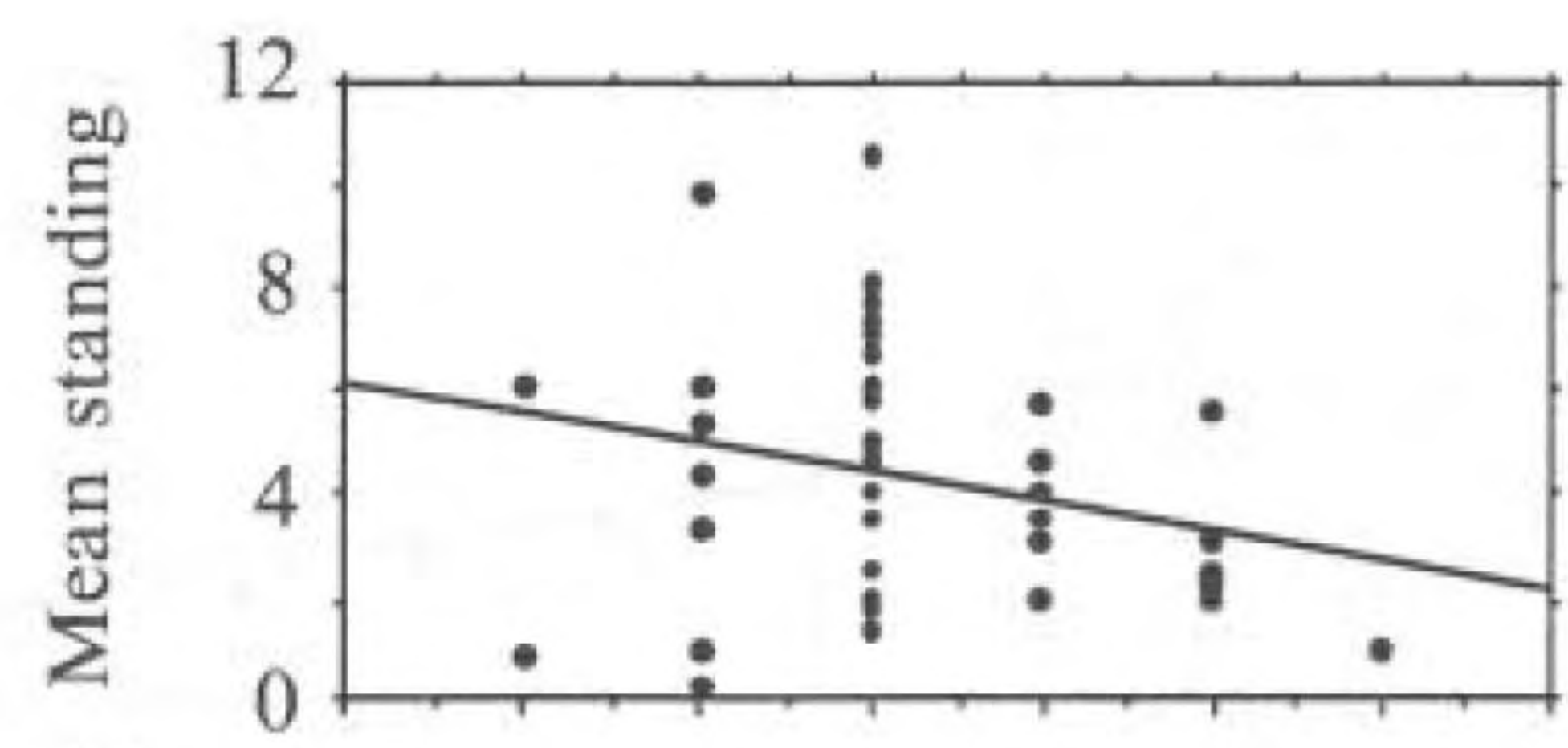

(b)

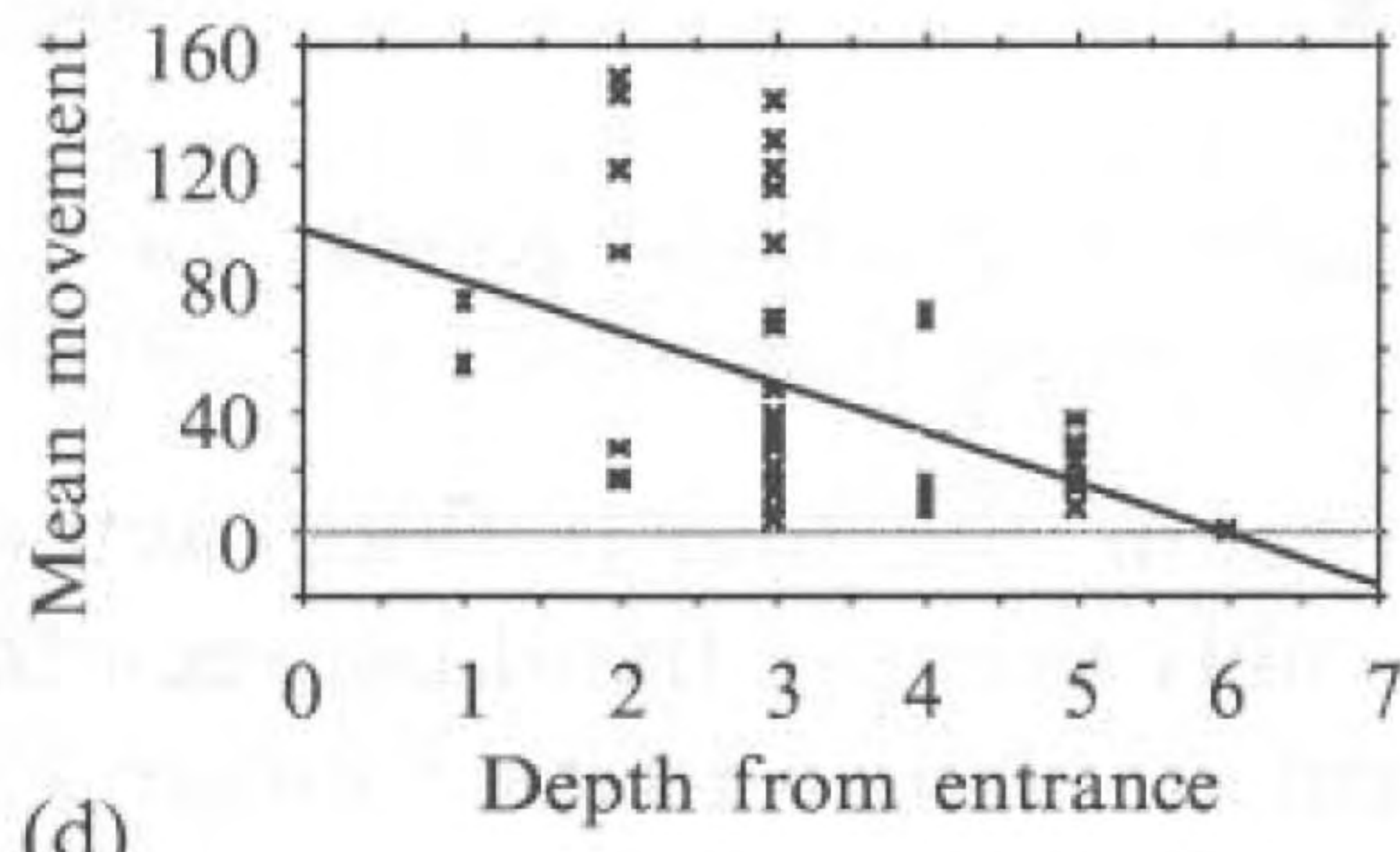

(d)

Figure 10. (a) Seated people and step depth from the entrance, $r=0.434, p=0.0021$; (b) standing people and step depth, $r=0.265, p=0.0692$; (c) talking people and step depth, $p=0.1418$; (d) movement and step depth, $r=-0.443, p=0.0015$.

These three scatters each show a predominance of all activities three steps from the entrance, which is important as a characteristic of the structure of the building: the lines in the building are on average three axial lines from the entrance itself without many routes much deeper than that. The maximum depth from the entrance is 6 , and only one line appears at this point in the scatter.

Movement is also at a maximum shallow to the entrance and then tails off with depth. For the whole building, there is a large range of average movement three steps from the entrance [figure 10(d)], reflecting the fact that most lines are at this depth and also that movement on the fifth floor occurs along the locally and globally integrated routes of the whole 'horseshoe' corridor space.

If we consider the fourth floor alone, movement is very strongly related to the depth from the entrance (figure 11). Movement falls off clearly with every step deeper into the fourth floor. Because the fourth floor is a smaller part of the building than the fifth, the depth from its entrance is strongly related to the structure of global integration of the two floors taken together. However, on the fourth floor the relationship between local and global integration seen on the fifth is missing. Moving people on shorter and longer trips on the fifth floor are channelled into the same space, whereas the only channelling of movement on the fourth is that of increased movement nearer the entrance.

The way in which the building channels movement differently on the fourth and fifth floors gives an important clue to the way that space affects the workings of the organisation in terms of patterns of communication. Figure 12(a) shows a clearly positive trend between observed movement and talking on the fifth floor, indicating that as people move around the floor they are brought into contact with conversation groups.

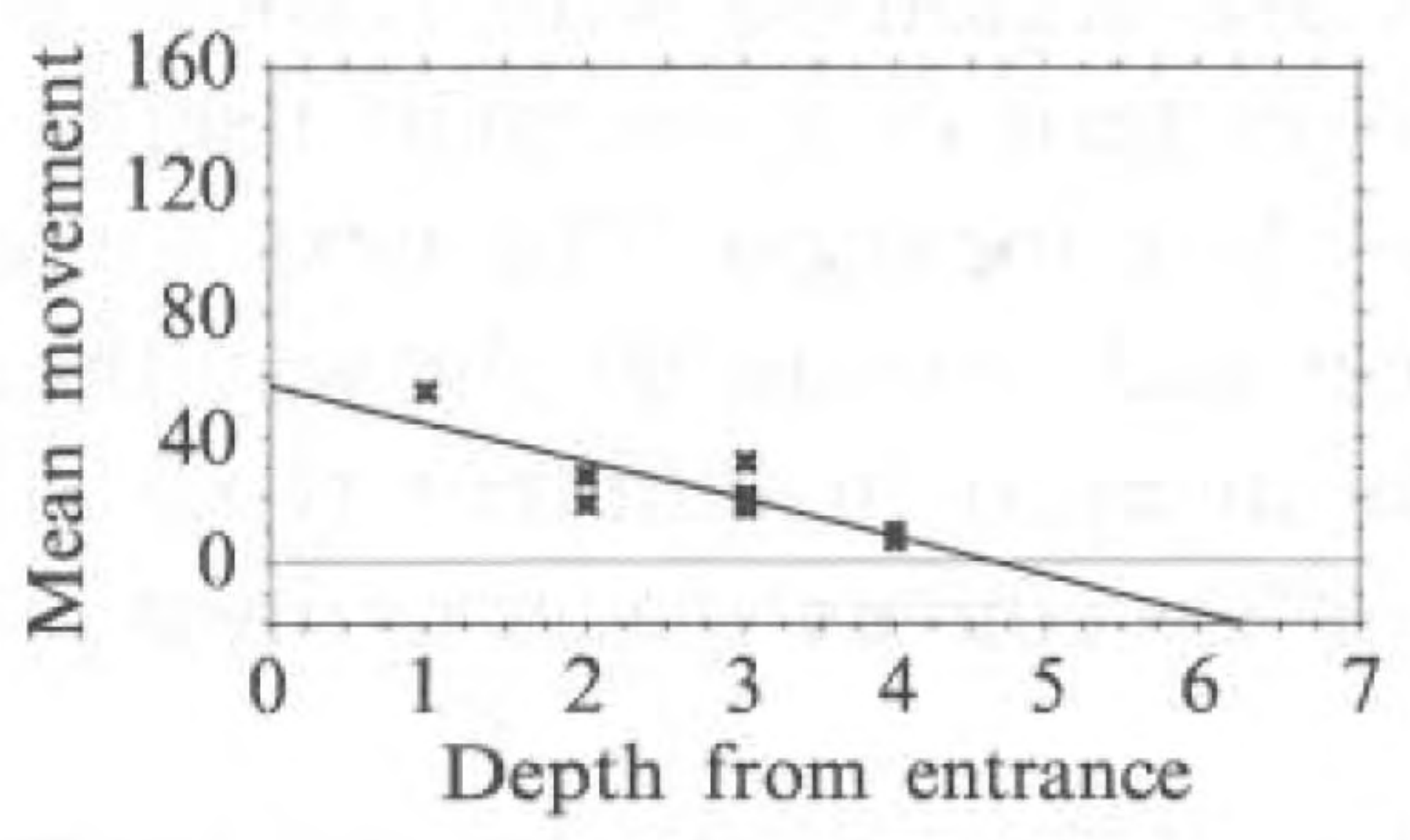

Figure 11. Movement and step depth from the entrance on the fourth floor alone, $r=0.837$, $p=0.0025$. 


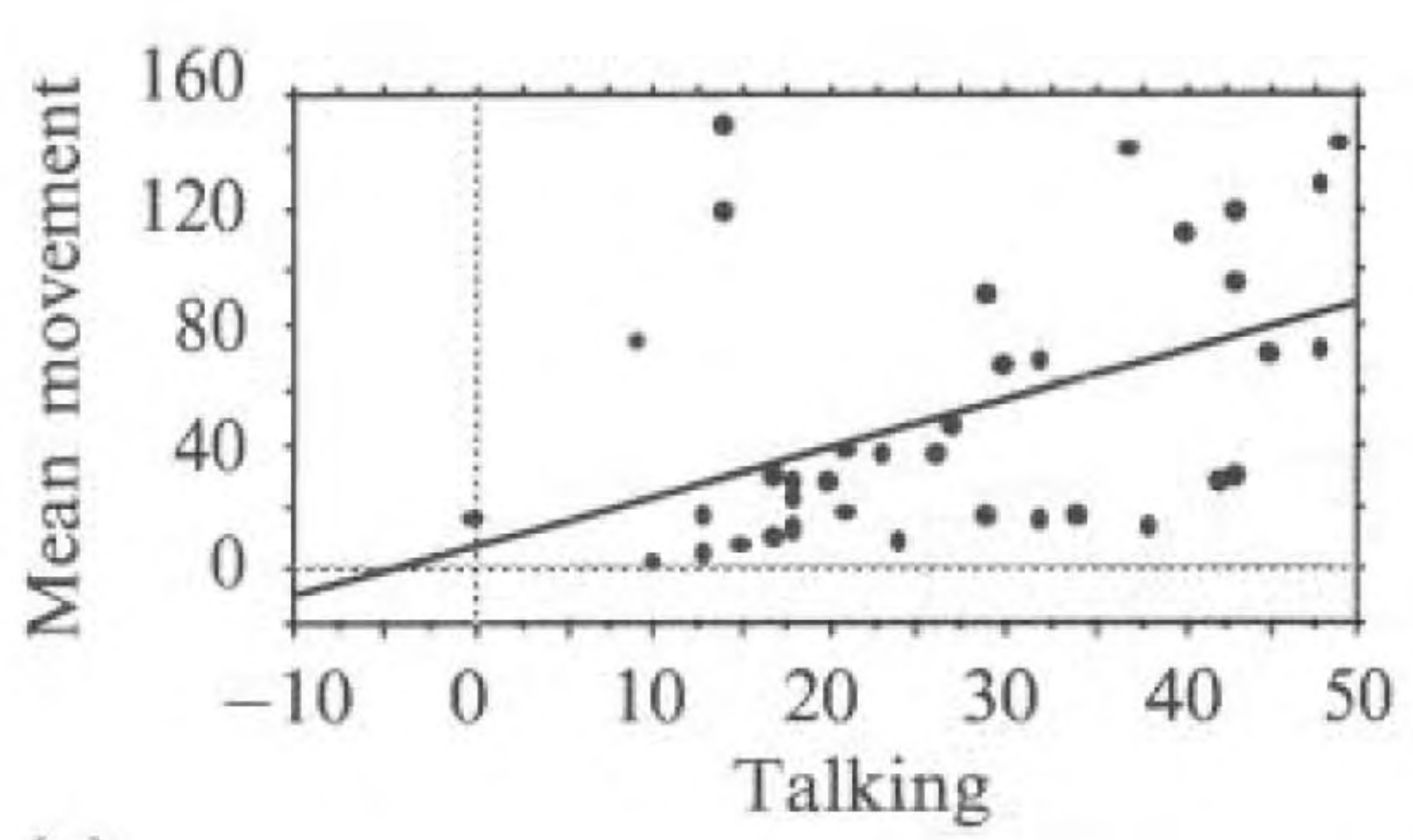

(a)

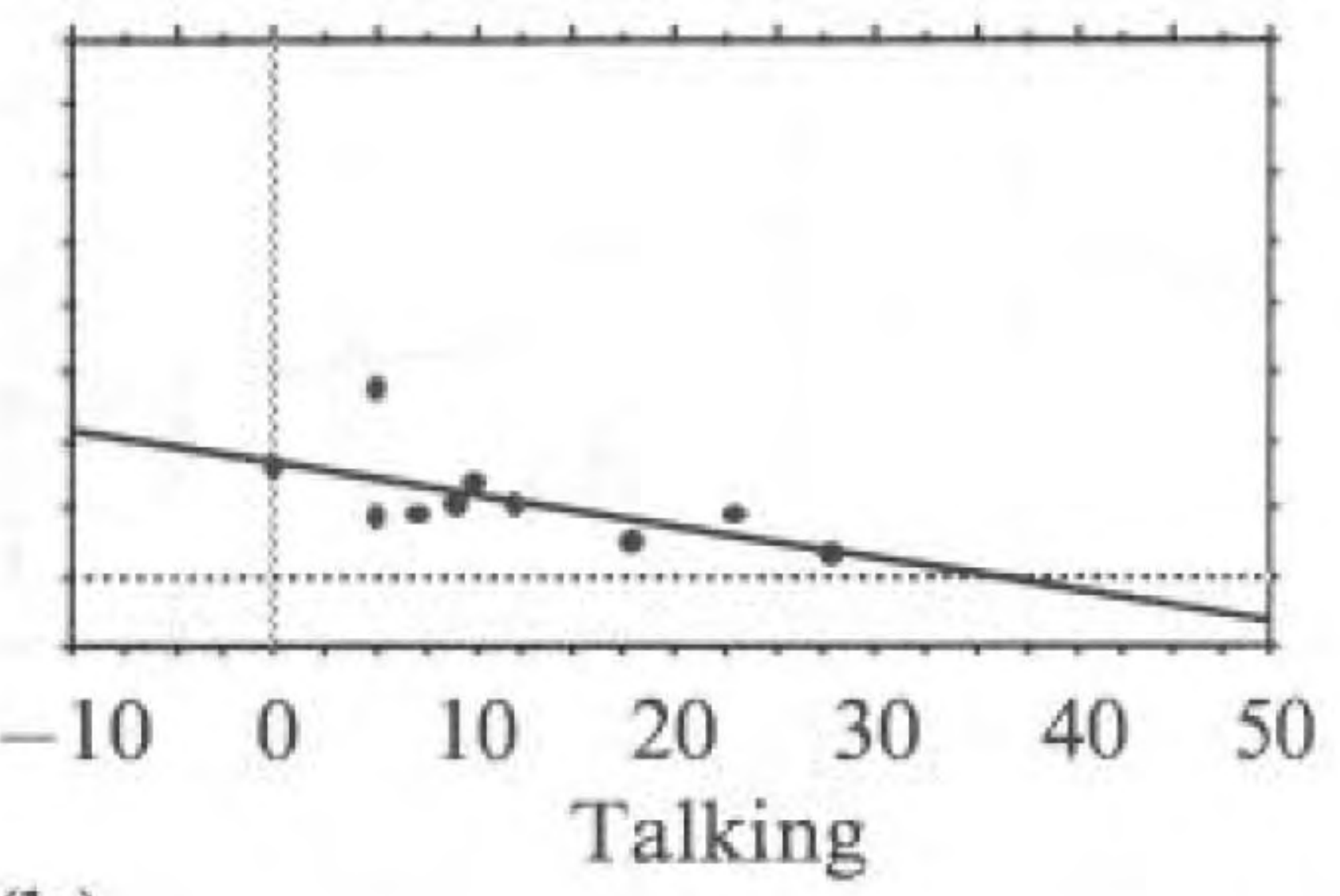

(b)

Figure 12. Mean movement and talking people for (a) the fifth floor alone, $r=0.458$, $p=0.0038$, and (b) for the fourth floor alone, $r=-0.612, p=0.0601$.

However, the structure of the fourth floor actually produces the opposite trend [figure 12(b)] with a visibly negative trend between the amount of talking along a route and the average movement along a route. Conversations and movement are effectively separated from each other.

This can be seen to be an effect of the way in which the corridor space is so strongly segregated from the normal workspaces by the silver screen wall. Although talking does take place at desk locations, these locations are separated quite dramatically from the main corridor movement. The effect is exacerbated by the way the pattern of integration into the rest of the building is separated from the pattern of local integration on the floor itself. This means that even local movement on the floor is effectively removed from in-to-out movement with the result that the spatial mechanism for engineering random contact and exchange of information has been practically eliminated.

Looked at in this way we can see movement as a resource which takes people past others' desk locations. This works as a randomising or 'shuffling' mechanism so long as patterns of movement and desk locations are themselves shuffled, and so long as movement is available to those seated at desks. As soon as one begins spatially to differentiate a building layout, two things follow. First, we may pull apart different patterns of movement, for instance, the in-to-out movement and the internal movement on the fourth floor, and so affect the probabilities that different groups of staff will meet. Second, we may create more and less desirable desk locations by giving these out to staff either according to status or according to the functional requirements of their job. Each of these tends to build in a more permanent structure that conserves a particular subdivision of the organisation by affecting the probabilities that different groups will see each other.

The first and most noticeable effect on the fourth floor is simply the removal of the 'generative' interface. The longer term effect of this type of spatial differentiation could be the fossilisation of particular organisational structures, thus inhibiting the ability of the organisation to evolve and respond to changing demands from its market.

\section{Facilities and resources}

The previous section has shown how it is possible to analyse the movement routes of the building as axial lines and to show how activities are organised with respect to these movement routes. It has been suggested that the pattern of movement itself is a key resource afforded by the building to a particular desk location. The next stage of the analysis is to move from routes to individual spaces and to consider the way that the building structures the availability of other people engaged in different types of activity. To do this, the building was divided into more or less convex spaces defined by workstations and partitions.

Just as one movement route passes through a number of spaces, any convex space may have a greater or lesser number of available routes that go into it. The number of 
other spaces that are linked directly to any space by axial lines will differ depending on how strategic the available lines are. The accessibility (and thus strategic value in the building as a whole) of a line can be measured by its integration. The sum of integration of all lines within a space is a very clear predictor [figure 13(a)] of the amount of movement that is available to someone in that space (the number of moving people that a person can see and move directly to). The relationship of available sitting people to the accessibility of a location is also positive, but a much messier fit than that of all the available movement [figure 13(b)]. This is because seated people tend to be in the less integrated spaces at the periphery. Although the more strategic lines will tend to link a space to more seated people, there are some strategic lines that do not have so many seated people along them, and vice versa. Thus seated people are not located as sensitively to accessibility as moving people and the seating locations vary more in the degree to which they are strategic. The total number of standing people available is more clearly linked to the accessibility of a location because standing people are more closely associated with movement than seated people [figure 13(c)], as standing usually implies that a person has just moved or is about to move. These results confirm what we have already noted on the observation maps: that movement is shallow, sitting is deep, and standing somewhere in between. The number of talking people available to a space is also well predicted by the average accessibility of its lines [figure 13(d)].

The implication of these correlations is that a person's location directly affects the possibility of contact with others. The more accessible spaces in the building have a greater number of people both visible and directly reachable. Figure 14 shows the powerful correlation between all people available to a space and the sum of line integration values of that space. This means that the spatial structure of the building

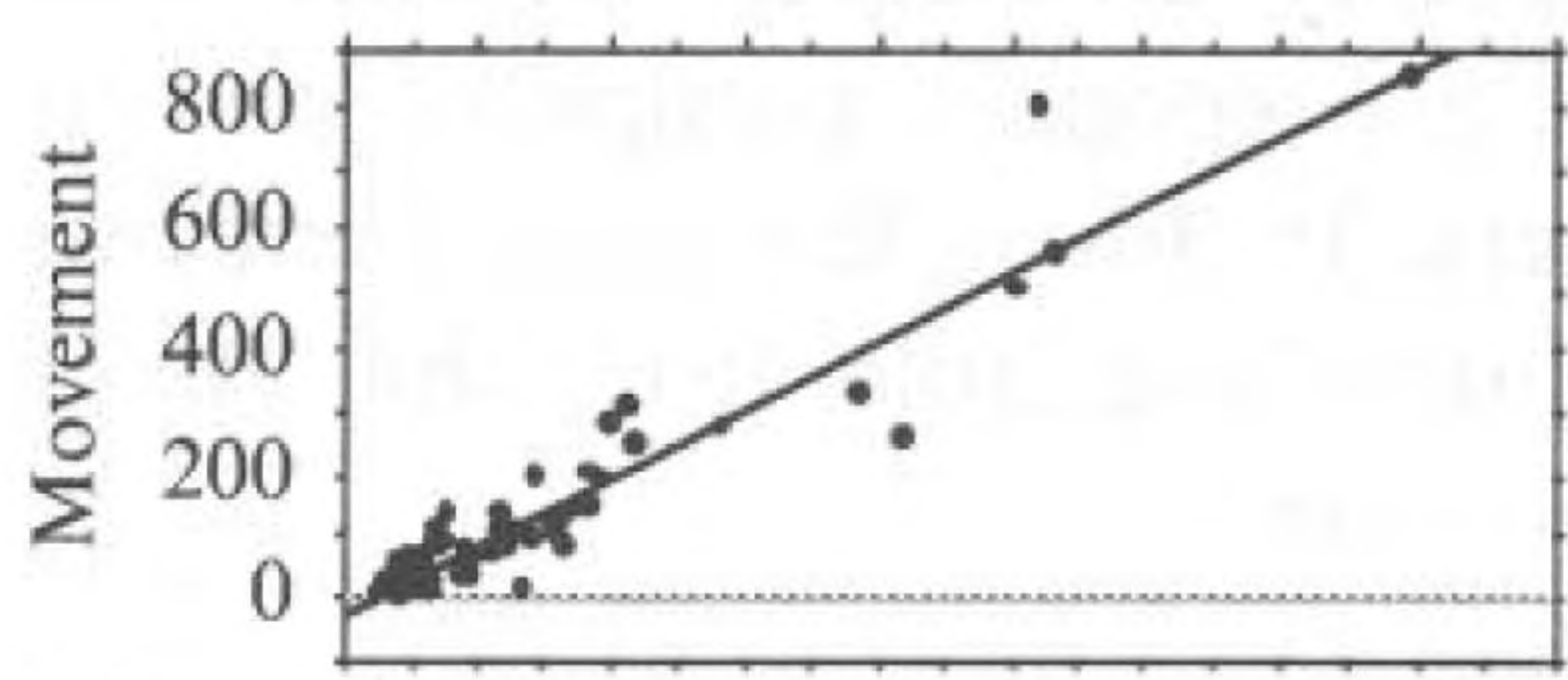

(a)

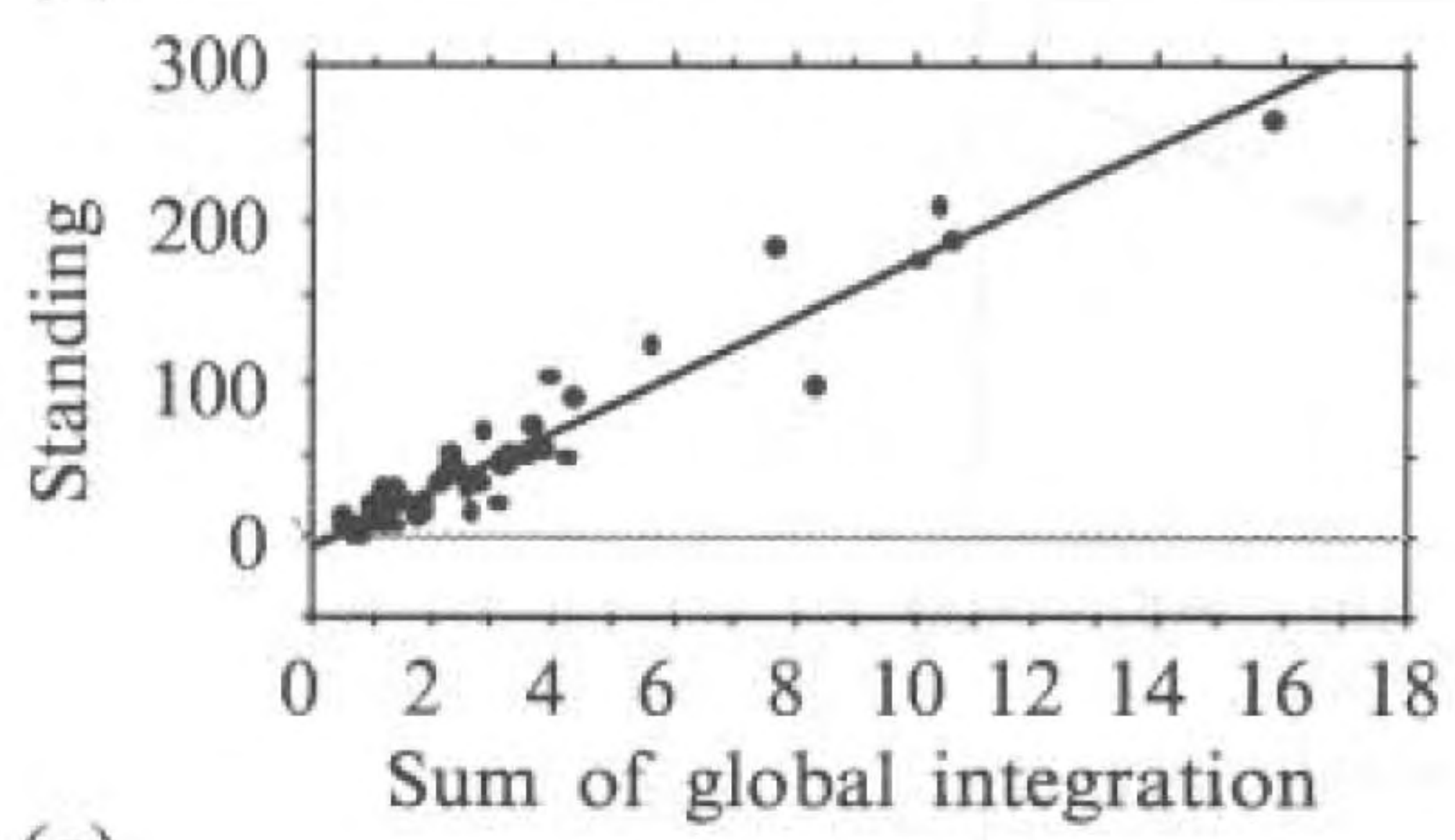

(c)

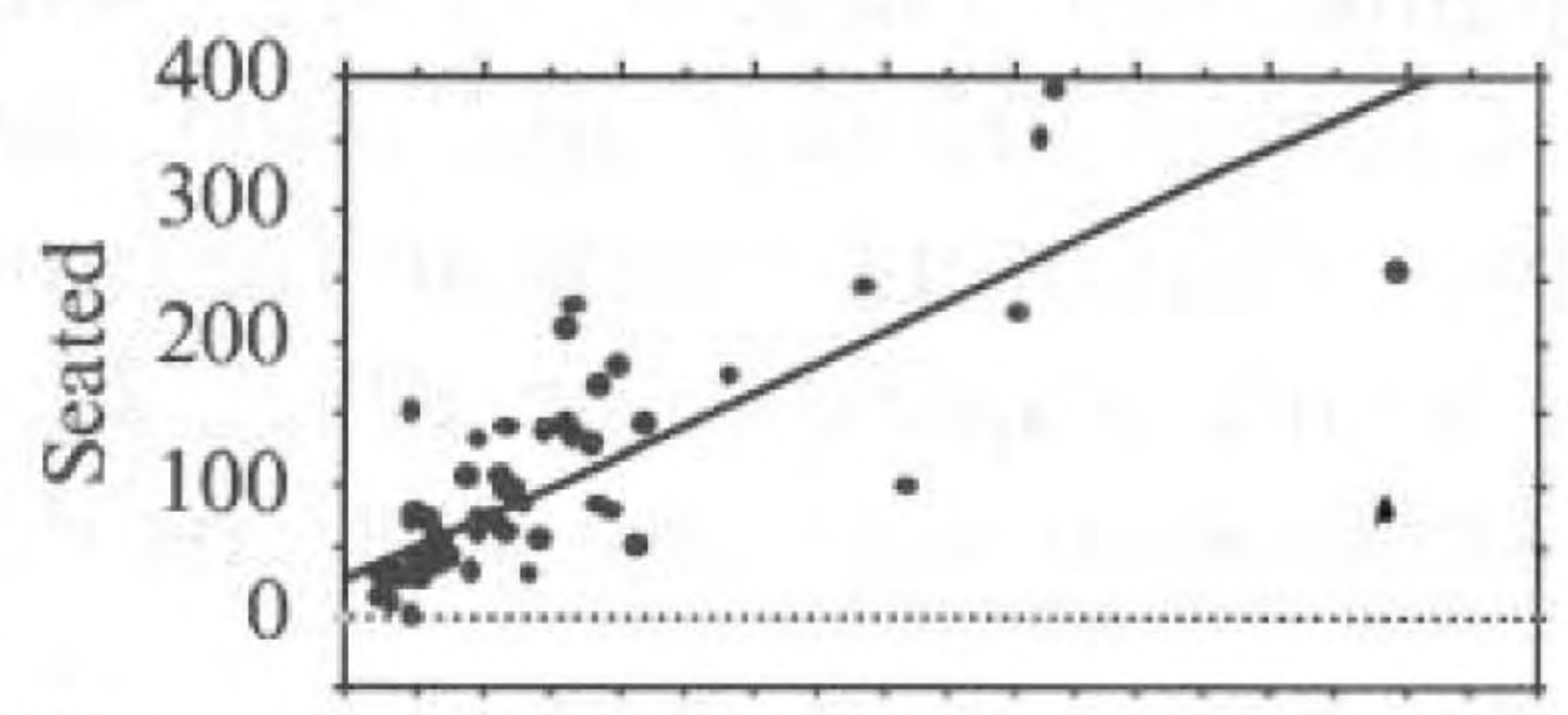

(b)

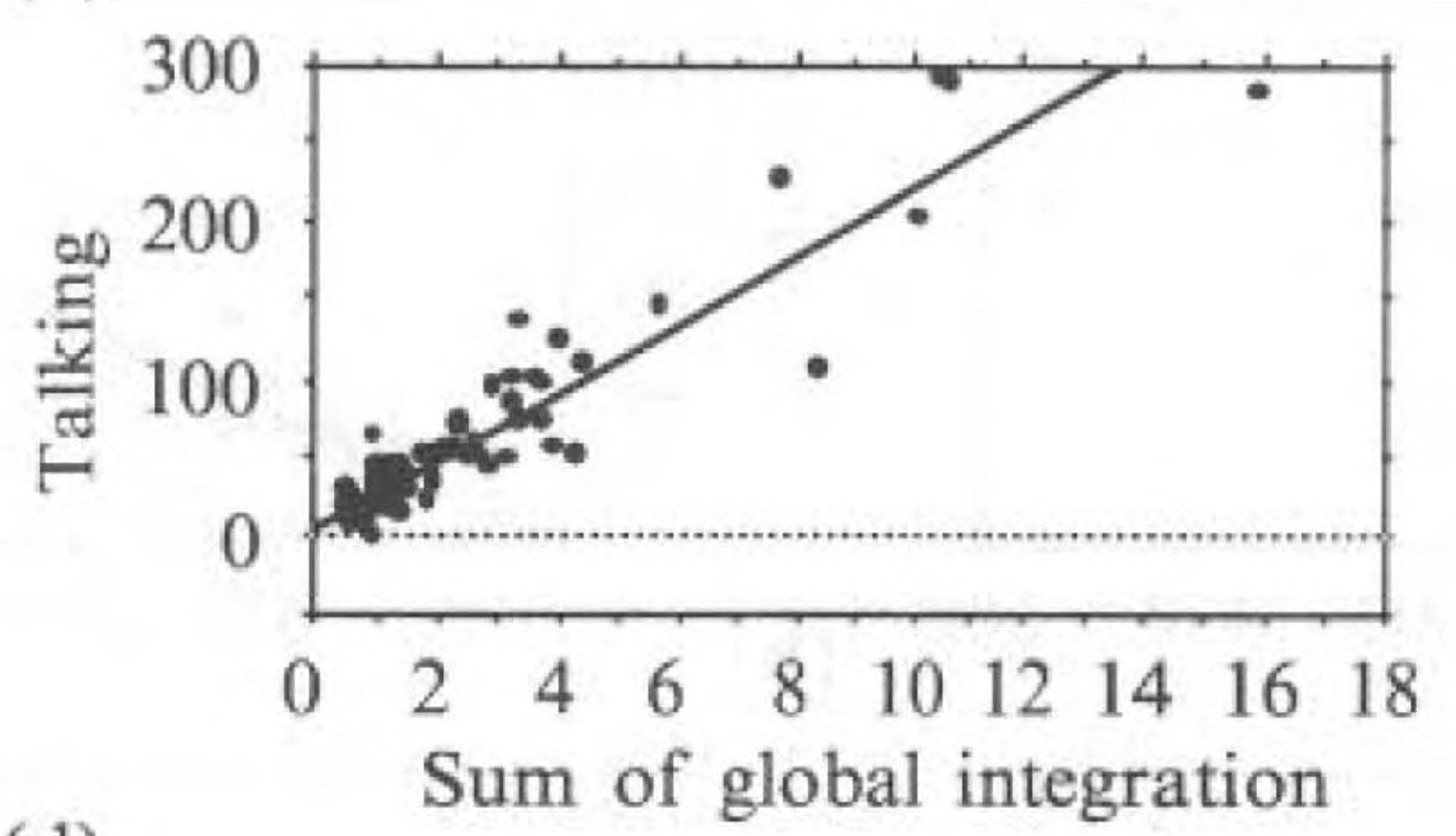

(d)

Figure 13. Sum of global integration of the lines that enter a convex space and: (a) the sum of all available movement from it, $r=0.951, p=0.0001$; (b) available seated people, $r=0.811$, $p=0.0001$; (c) available standing people, $r=0.963, p=0.0001$; and (d) available talking people, $r=0.929, p=0.0001$.

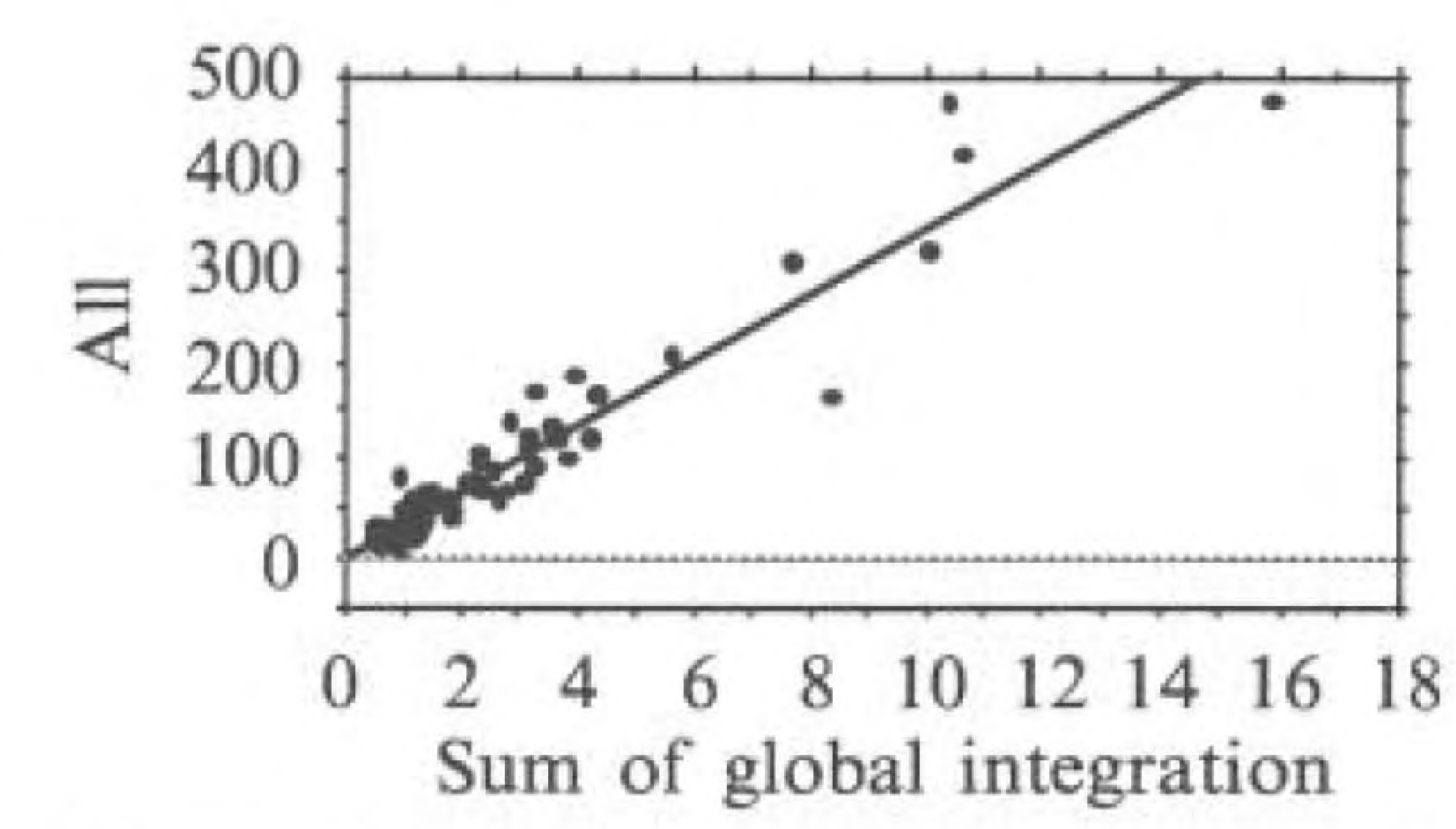

Figure 14. All available people and sum of line integration, $r=0.966, p=0.0001$. 
can integrate or segregate people from other people, controlling their availability by spatial differentiation.

These effects might seem fairly simple. However, they become more complex when different categories of people have differential access to different parts of a building. The cellular offices allocated to the creatives are a case in point. The creatives have a relatively privileged position in the organisation as they can choose either to segregate themselves in their offices or to move through the more public areas and take advantage of the presence and availability of others to generate interaction.

The effect of the higher degree of variation in different sitting locations so far as availability is concerned is shown through the relative dispersion of the scattergram in figure 15(a). In some spaces (those above the regression line) available people are mainly seated, in others the majority are not seated, and this varies quite radically from location to location. Other categories of activity such as movement [figure 15(b)], static [figure 15(c)] and talking people [figure 15(d)] are all much less differentiated in their locations so far as availability to others is concerned. The clearest relationship is between talking people available from a space and all people from a space [figure 15(d)]. This shows, first, that interaction arises out of presence of people, and, second, that interaction is only spatially differentiated according to the degree that presence or absence of people in general is spatially differentiated.

If people are to be considered as a resource, and interaction as the way that this resource is made use of, then the function of spatial differentiation appears to be to modify or control the way that the resource is used. In this sense we might consider the spatial differentiation of the work environment as constituting a 'facility' which conserves and brings human resources to bear in the requisite mass to tackle the specific tasks posed by the organisation. These tasks are undoubtedly 'structured': at times one requires interaction, at others privacy; and often there are specific groups of people that need to interact but without interruption from others. If this is the case, then one might expect activities within a space to be affected by those 'available' from that space in some more or less structured way, and so to be detectable.

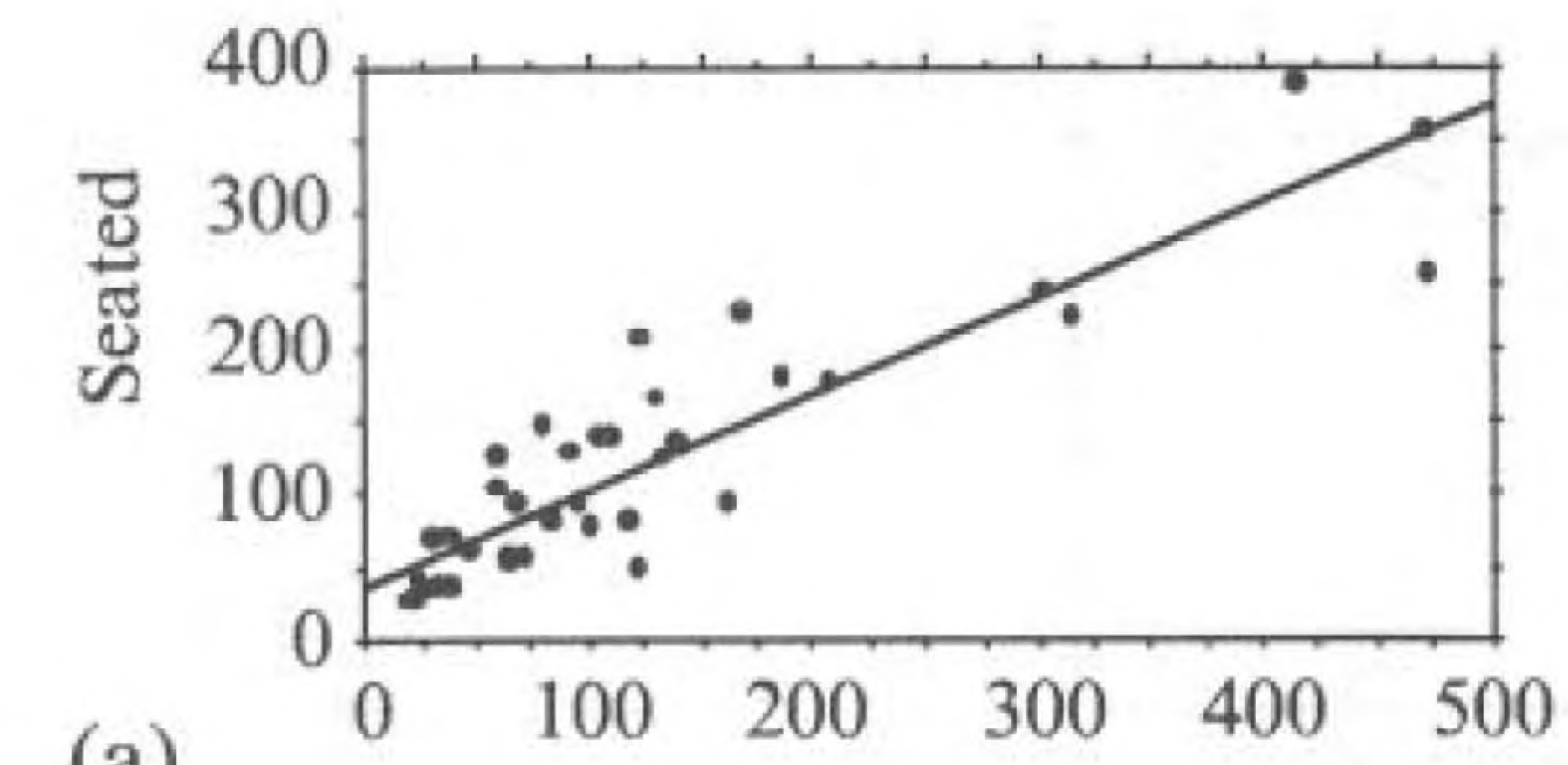

(a)
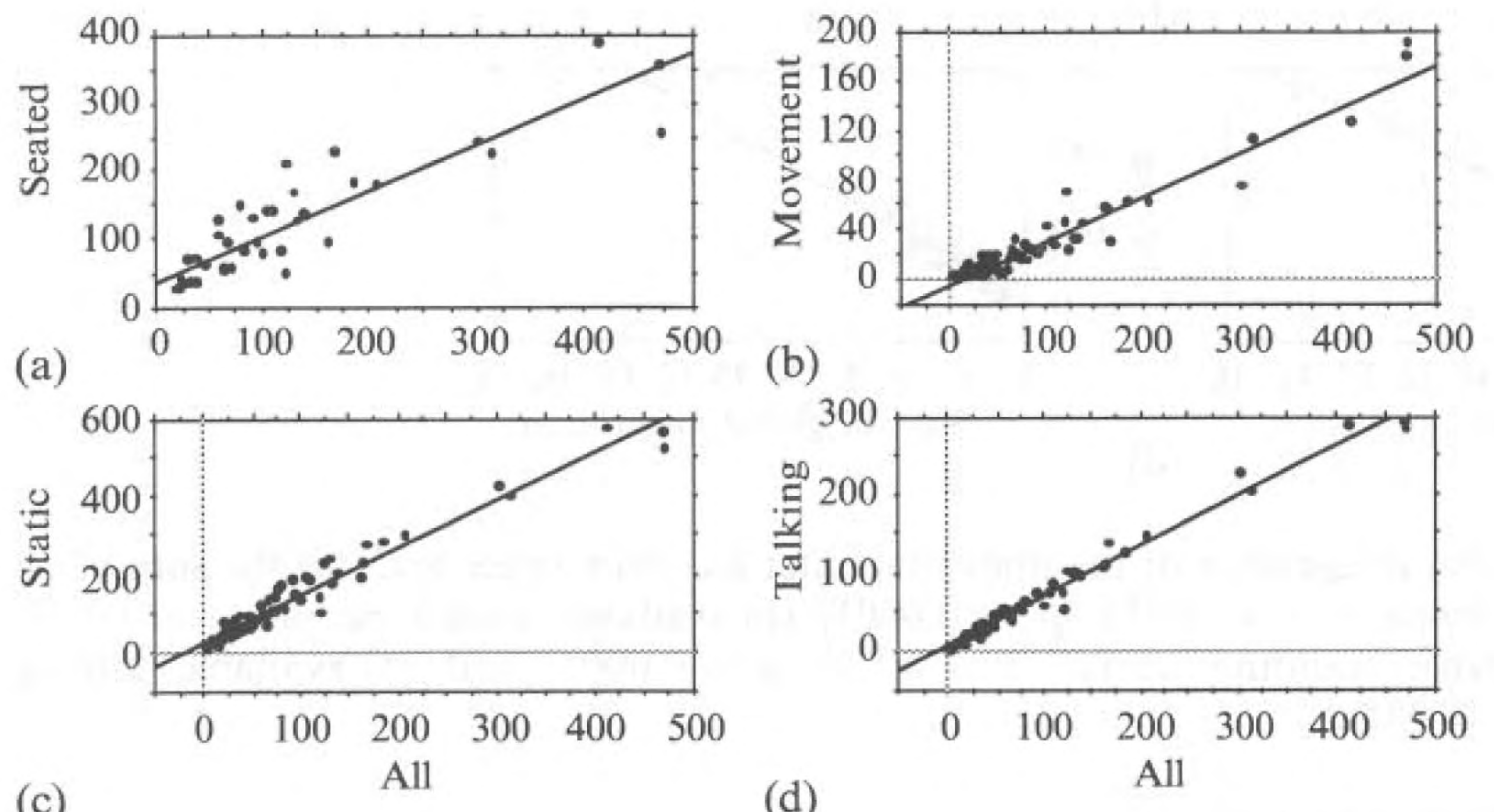

(c)

(d)

Figure 15. All available people and

(a) all available seated people, $r=0.899, p=0.0001$;

(b) available movement, $r=0.966, p=0.0001$;

(c) available static people, $r=0.975, p=0.0001$;

(d) available talking people, $r=0.989, p=0.0001$. 


\section{Differentiation of space and activities}

The number of people available - all those visible and directly reachable - from a space can be compared with the activity that takes place within the space itself. This effectively compares what is going on in a space with what is going on in and around it. Figure 16(a) shows the relationship of all talking within a space to the total availability of people in and around it. The scattergram is clearly split into an L shape. The split distinguishes two different types of space. In the upper limb of the scatter, the number of talking people in a space rises with little increase in the number of available people around it. In the lower limb, the number of people available around the space outstrips those talking within it by a large margin. This means that there are some spaces where the only people available are those that are talking within the space itself. These are the meeting rooms and cellular offices.

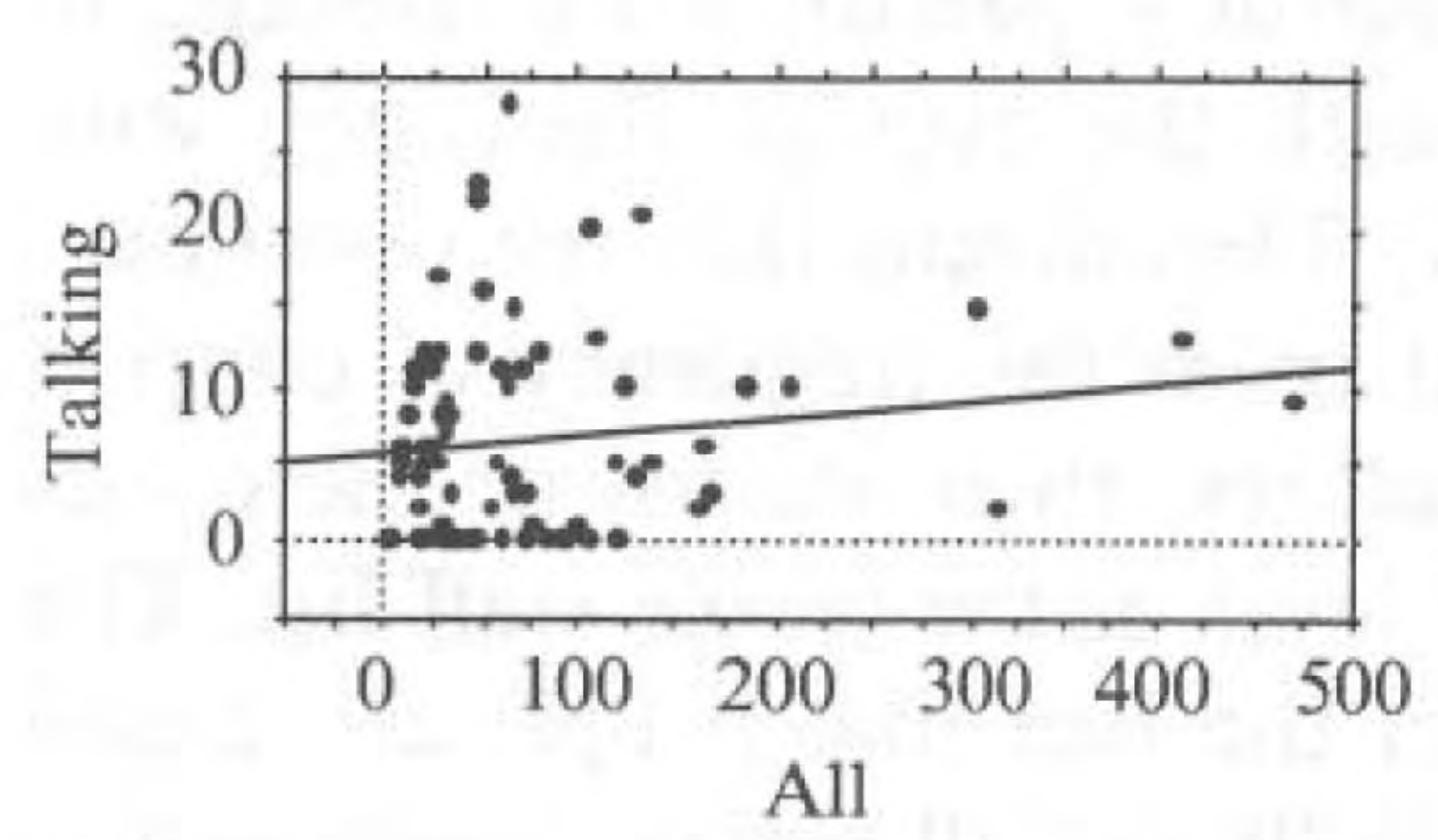

(a)

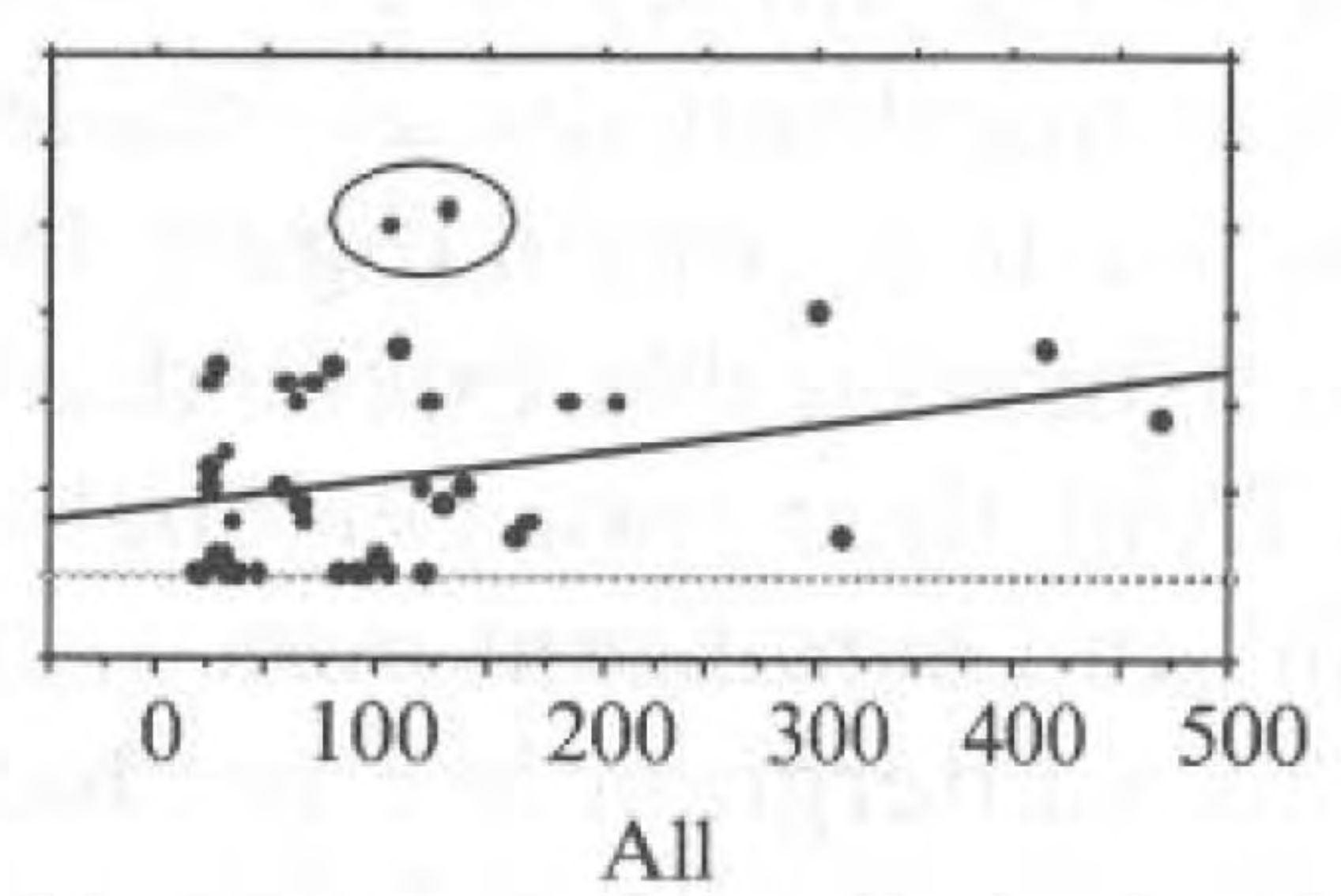

(b)

Figure 16. Relationship between those talking within a convex space and: (a) all available to that space by means of the lines that enter it, $r=0.161, p=0.147$; (b) all available people, fifth floor open-plan areas only, $r=0.313, p=0.036$.

Obviously a meeting as a programmed event seeks to minimise disturbance by other 'available' people. This can be seen in the scatter of the fifth floor with the meeting rooms and cellular offices removed [figure 16(b)]. Much of the upper limb of the scatter has gone. The scatter is still fairly dispersed with some spaces having relatively high numbers of talking people and fewer available people than one might expect. These turn out to be parts of the general open-plan area that, owing to their isolation, are more or less like cellular spaces. This is particularly the case for the two outliers circled on the scatter which are effectively walled in to become quite distinct bays as the furniture and storage is beginning to restrict their available lines of movement.

On the fourth floor, the general open-plan spaces alone still exhibit the bifurcation. The majority of the unprogrammed spaces (circled on figure 17) are behaving more like meeting rooms or programmed spaces: the only talking available to them is within their own space. This is a direct effect of the silver screen wall and the narrowness of the front and back corridor spaces. The effect is to more or less limit interaction to that between neighbouring desks or to planned meetings taking place at a desk.

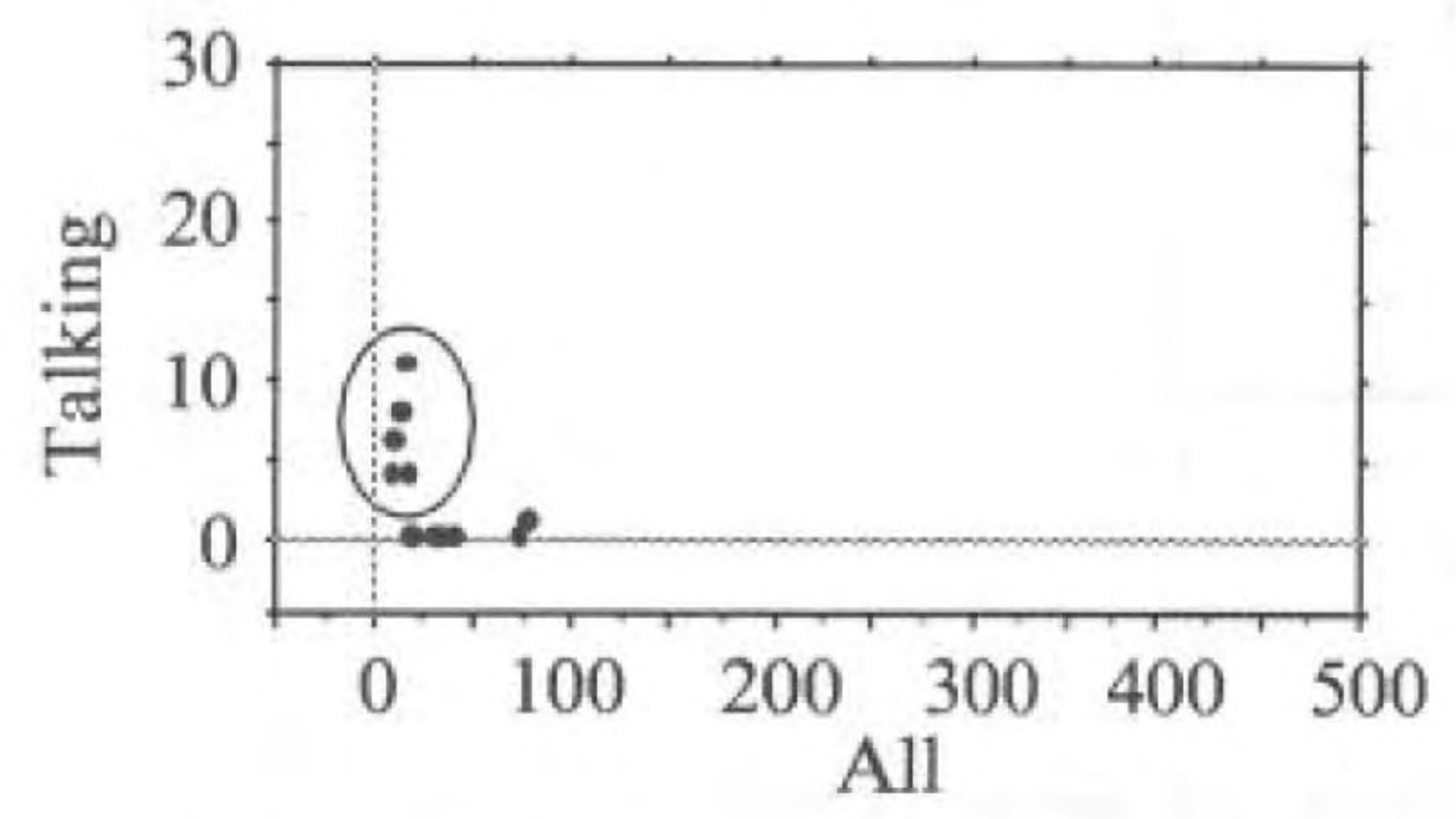

Figure 17. Talking people within a convex space and all available people, fourth floor open-plan areas only, $r=0.443, p=0.1296$. 


\section{Useful communications}

In order to examine the network of contacts between people working at company $\mathrm{Y}$, a questionnaire was created and distributed among staff. The questionnaire method precisely mirrored previous surveys in scientific research laboratories, and this in principle allows a comparison of results between the two different organisation types. The questionnaire listed by name all staff in the company. Respondents were asked to tick a box on a one to five scale (daily to never) to indicate how frequently they saw each person named, to indicate whether they found them useful in their work, and whether they worked with them regularly. The last question was asked in order to be able to separate out citations of usefulness of people within an individual's project team or working group, and citations of usefulness by those who did not have a direct working relationship with the person concerned.

An important finding of the survey is that how useful a person is on average to everyone who answered the questionnaire correlates with the average frequency with which people say that they see that person [figure 18(a)]. This means that the usefulness of a person is at least to a measurable extent derived from the frequency of contact with others and not just from their own personal qualities, their status, or their job. The trend is very powerful and significant even at the level of the whole staff list. The degree of dispersion of this scattergram is a product of the fact that people are useful because of other things: their status, knowledge, and skills are all clearly important.

If we look at the whole company, but this time exclude founder partners [figure 18(b)], we can see that the relationship is improved. If we consider the founders alone [figure 18(c)], their usefulness is much greater than the average, although it is also related to the frequency with which they are seen, but at a much lower slope (a much greater change in frequency of contact is required to make a change in degree of usefulness than for the organisation as a whole). In this case, the founders' experience, authority, or status are all clearly factors that mean that frequency is a less important element in constructing their usefulness. The two points on the scatter above the regression line are two partners based on the fourth floor, who are perceived as more useful than the frequency of contact might suggest. This may be in part an effect of the relative isolation of the fourth floor.

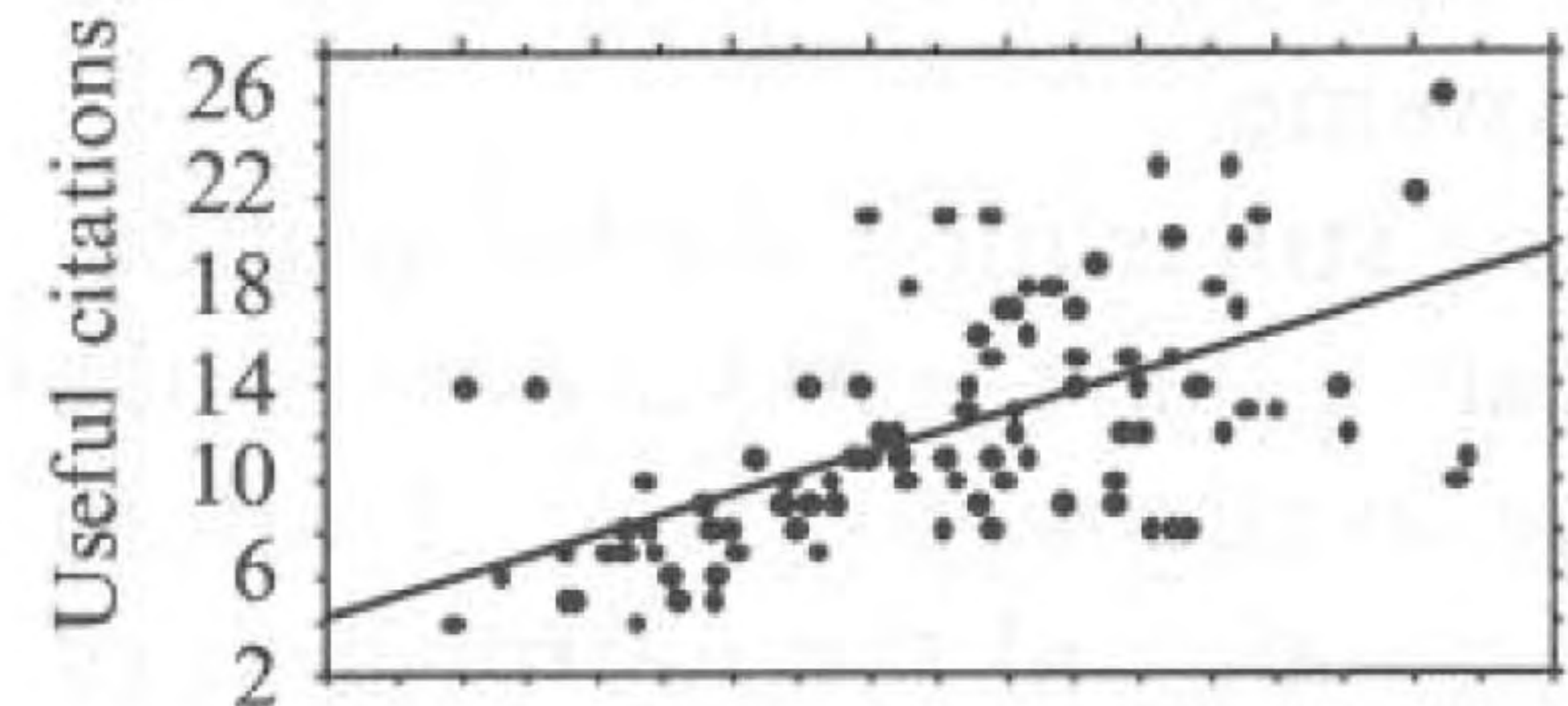

(a)

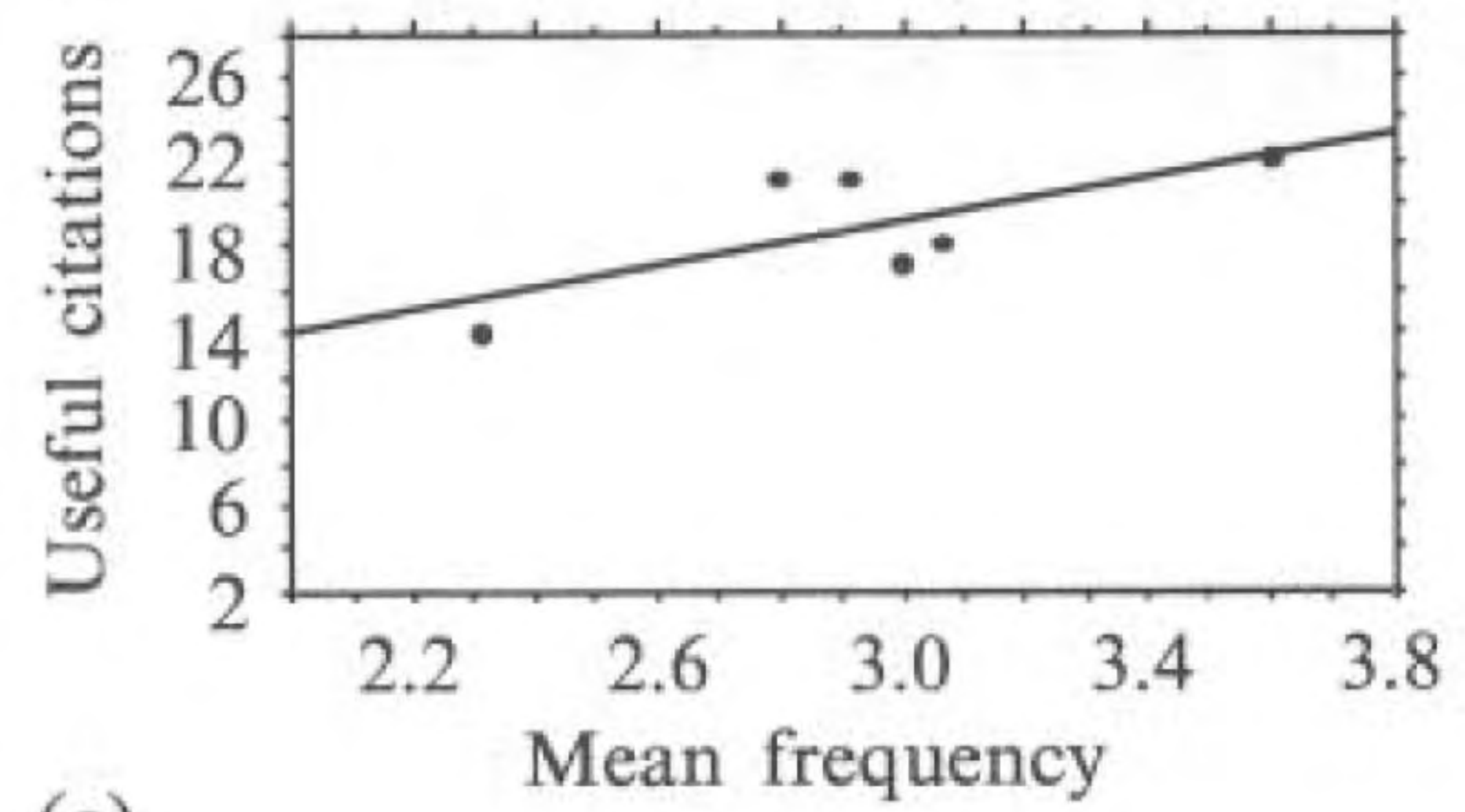

(c)

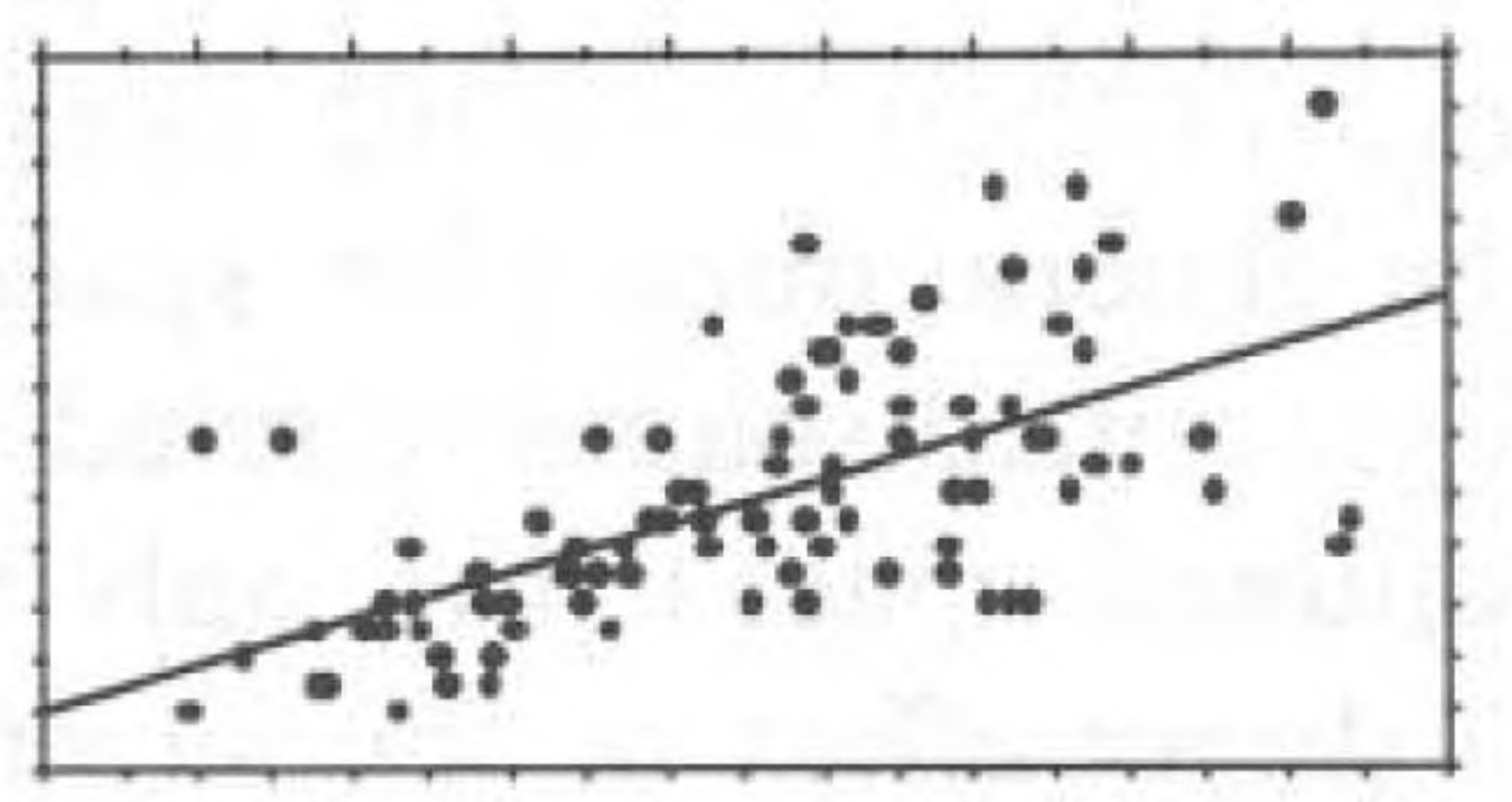

(b)

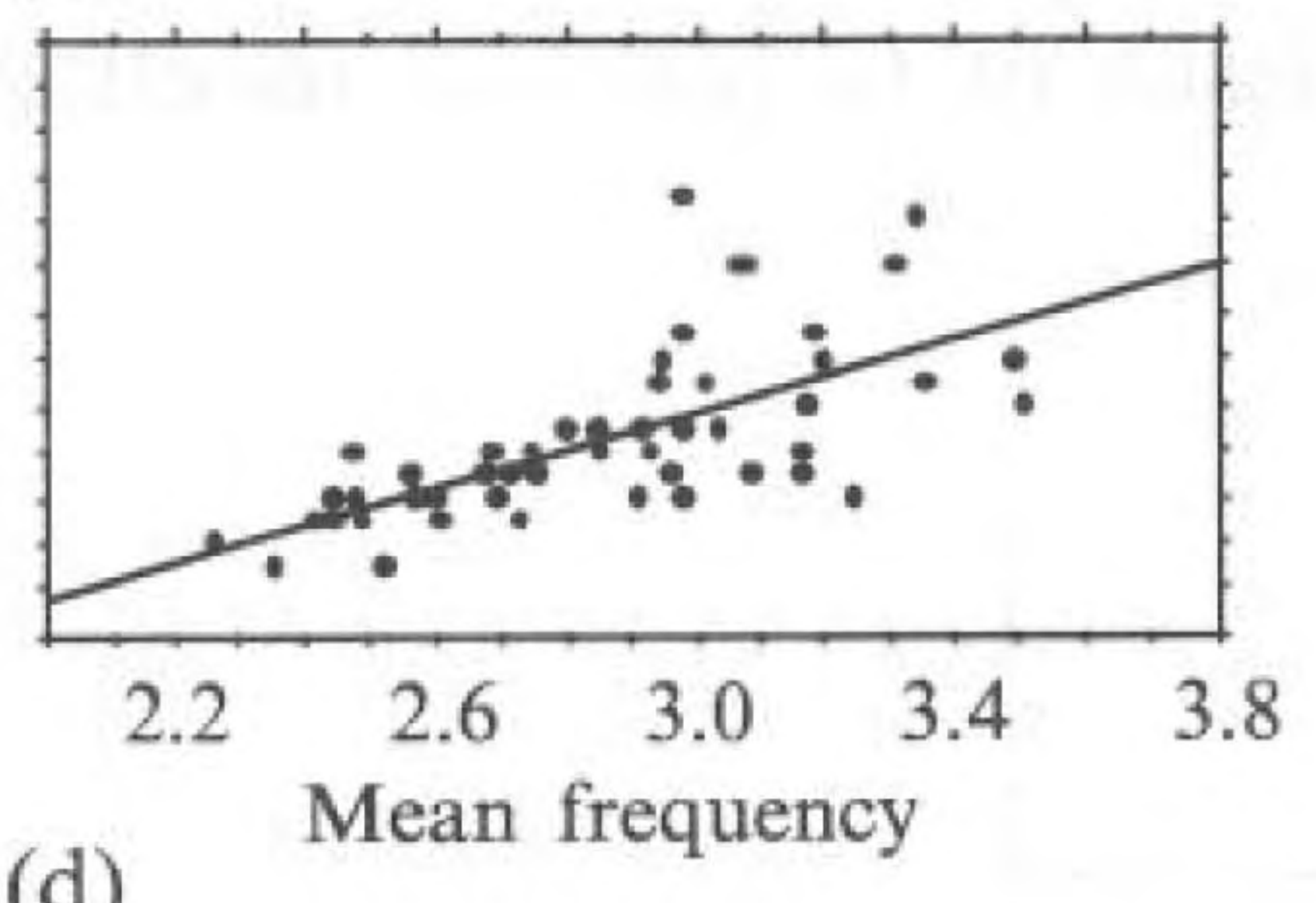

(d)

Figure 18. The total of 'useful' citations and the mean frequency of being seen:
(a) for all members of staff, $r=0.596, p=0.0001$;
(b) excluding founder partners, $r=0.627, p=0.0001$;
(c) for founder partners only, $r=0.711, p=0.0001$;
(d) for single-account staff only, $r=0.667, p=0.0001$. 
If we look at those staff that deal with single campaigns or accounts, the correlation between usefulness and frequency is maintained [figure 18(d)]. It is also clear that at the more frequent end of the scatter the degree of dispersion is greater.

However, when we abstract only the creatives, then their usefulness shows a very strong relationship to frequency and forms the lower tight end of the scatter (figure 19).

This suggests that the effect of the creatives' cellular office locations is to limit their frequency of contact but, given that, their usefulness follows frequency fairly directly. There are two significant outliers. These are the founder partners who are also creatives. Both are well above the regression line which is consistent with their role in the organisation; however, they have very different frequency citations. This is due to one of the partners who has spent a good deal of time away during the last six months and is seen much less frequently than one who stayed, who in turn is seen much more frequently than most of the rest of the creatives. This may in part be due to the fact that both partners have given up their cellular offices in favour of desk locations in the openplan area on the fifth floor. They were the only creatives to have done this at the time.

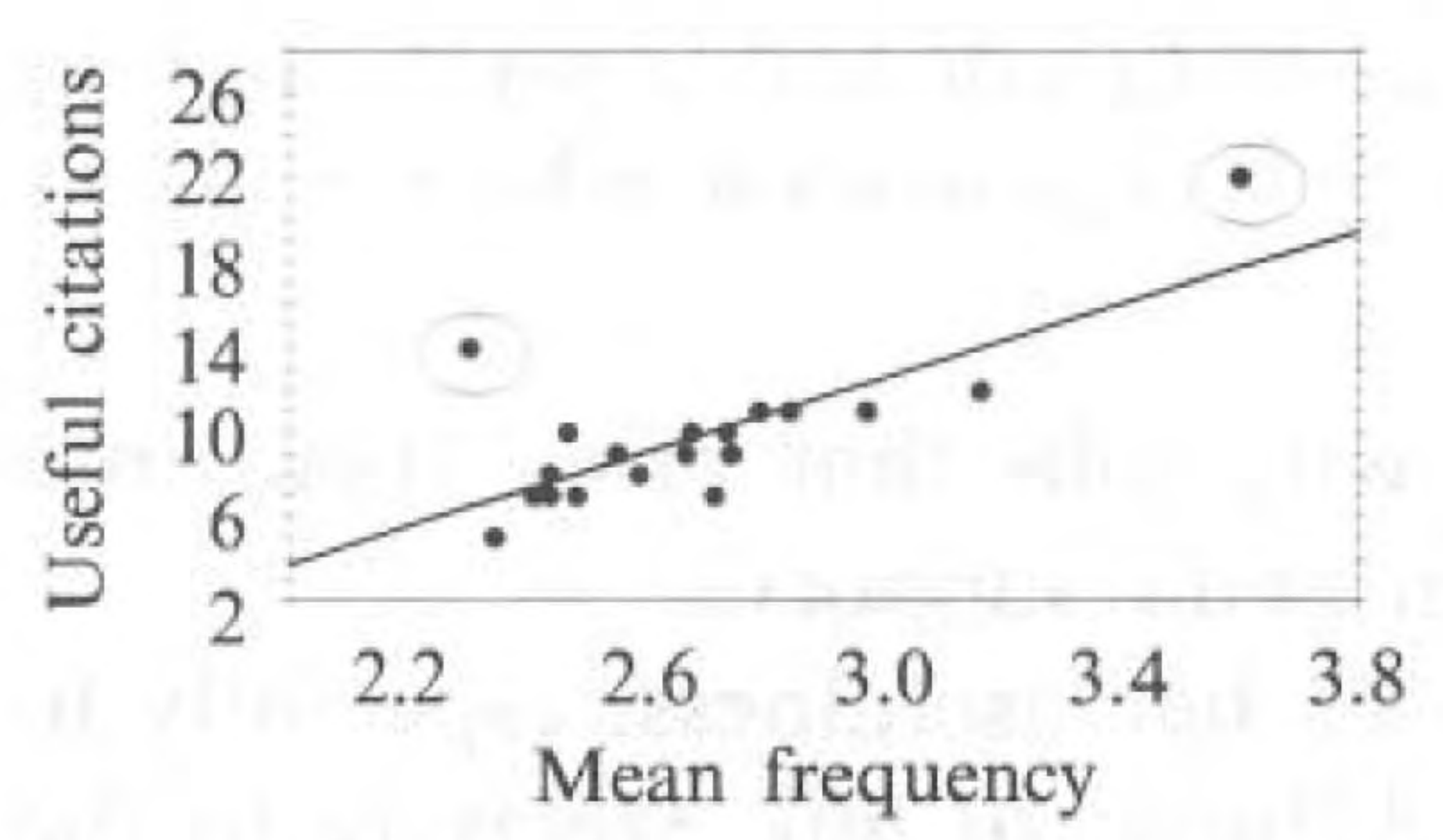

Figure 19. The total of 'useful' citations and the mean frequency of being seen for creatives only, $r=0.752, p=0.0001$.

If we look at single-account staff on the fourth floor alone, then we find a strikingly direct relationship between frequency and usefulness [figure 20(a)]. This suggests that, in the more cut off fourth floor, by far the most important factor in perception of usefulness is the degree to which one is seen, and that this begins to outweigh other factors such as experience and personal skills.

One of the strategies of company $\mathrm{Y}$ is to create 'spin-off' companies to develop particular specialist services for clients, such as event management or public relations. A number of spin-off companies use space in $\mathrm{K}$ house. If we consider these spin-off companies alone we find that they too show a very strong relationship between usefulness and frequency, perhaps because they are more independent in work and therefore have less usefulness derived from programmed working contact and more from casual helpfulness [figure 20(b)]. Again it seems that, as direct usefulness is removed from the equation, this time by an organisational split, the main factor in one's usefulness to others becomes the frequency with which one is seen.

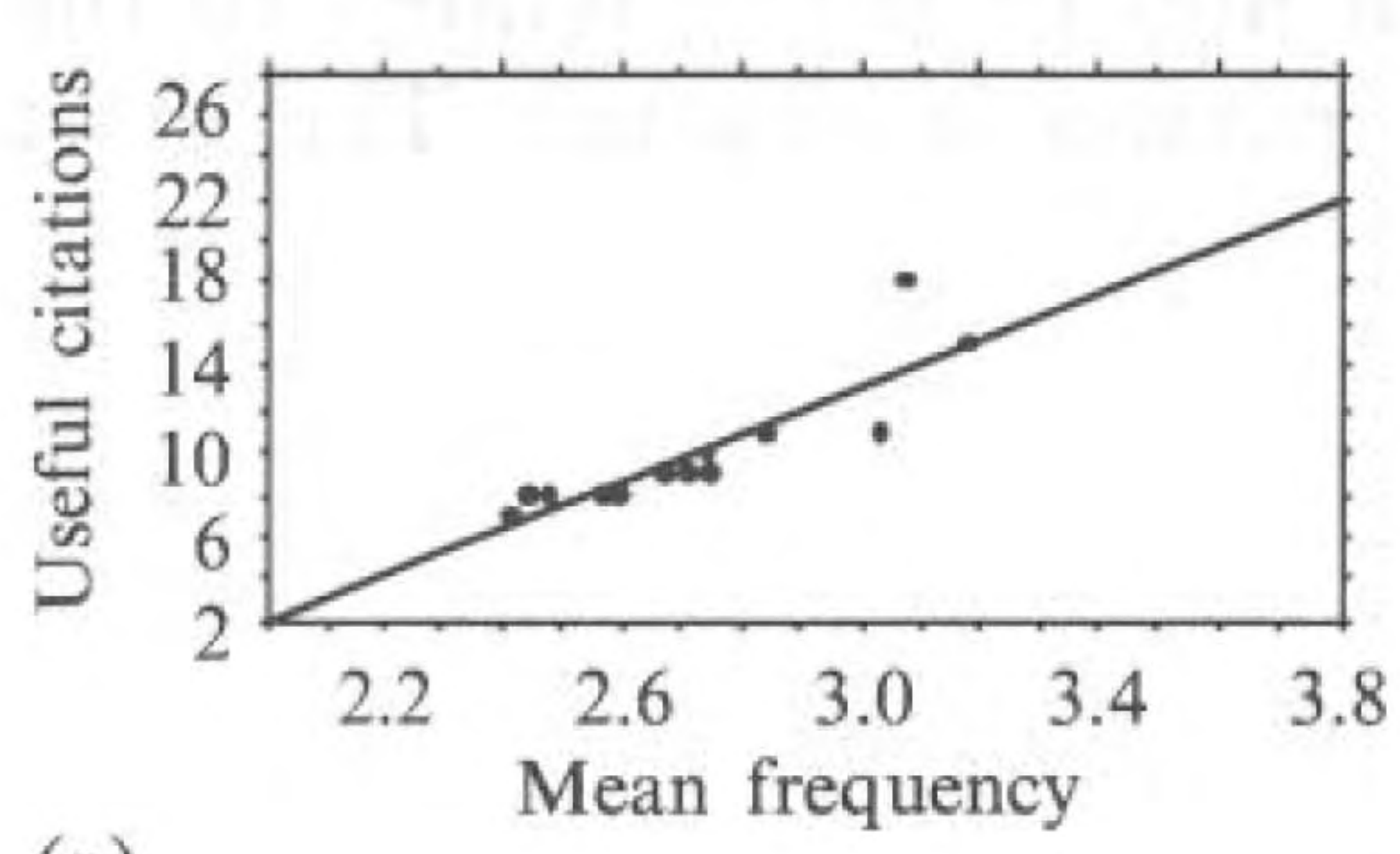

(a)

Figure 20. The total of 'useful' citations and the mean frequency of being seen: (a) for singleaccount staff on the fourth floor only, $r=0.877, p=0.0001$; (b) for 'spin-off' staff only, $r=0.865, p=0.0001$.

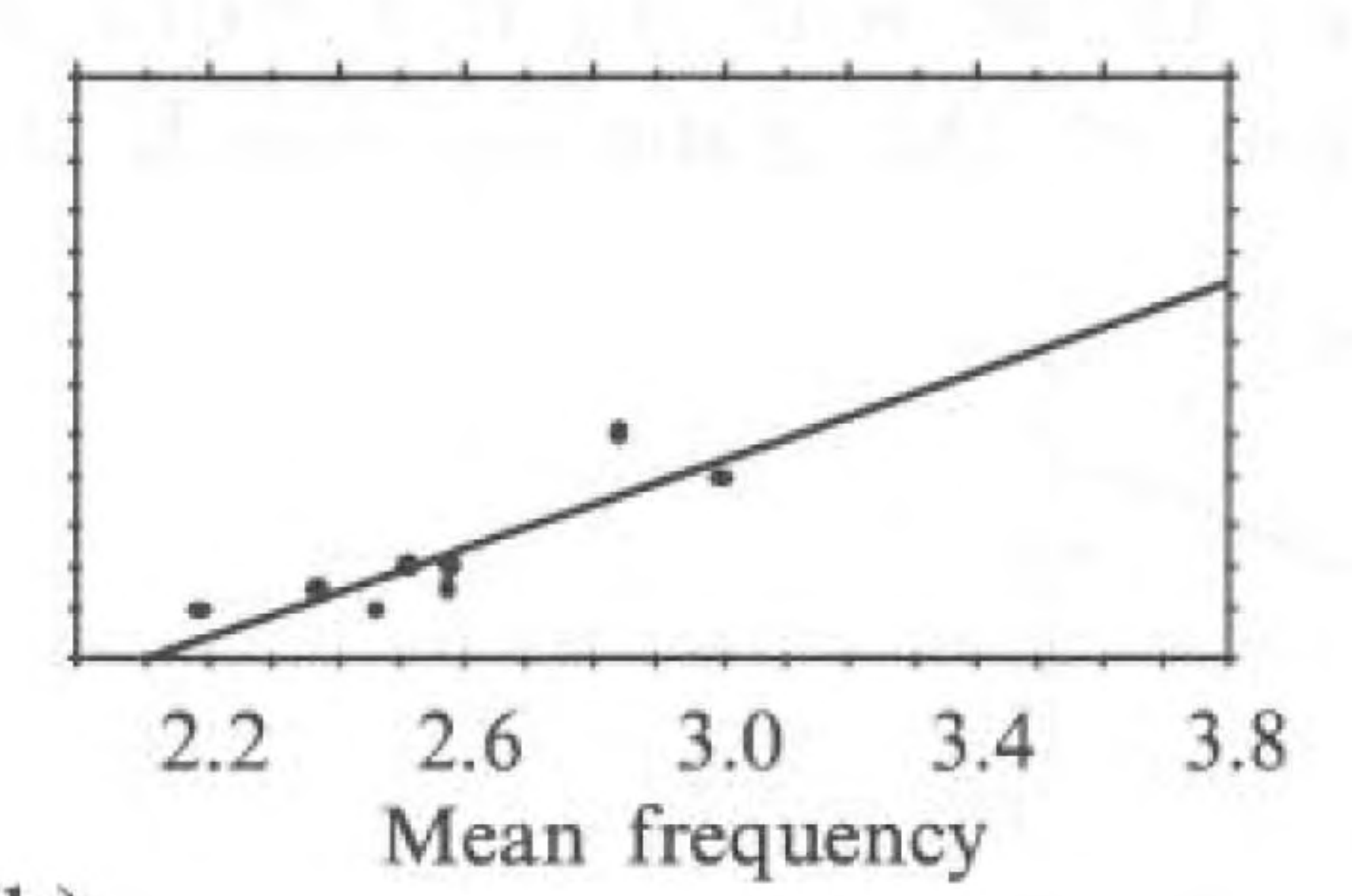

(b) 
One of the important kinds of contact between people in innovative organisations is that between people who do not have programmatic reasons to work together. The extent to which this kind of contact is taking place can be investigated by looking at the extent to which people are found useful by others who do not work with them directly. This kind of contact is dependent on seeing people frequently because unprogrammed discussion can take place only if people have a chance to 'bump into each other' in the building. Figure 21 shows a positive correlation between the average frequency with which someone is seen and his or her usefulness to those who do not work with that person.

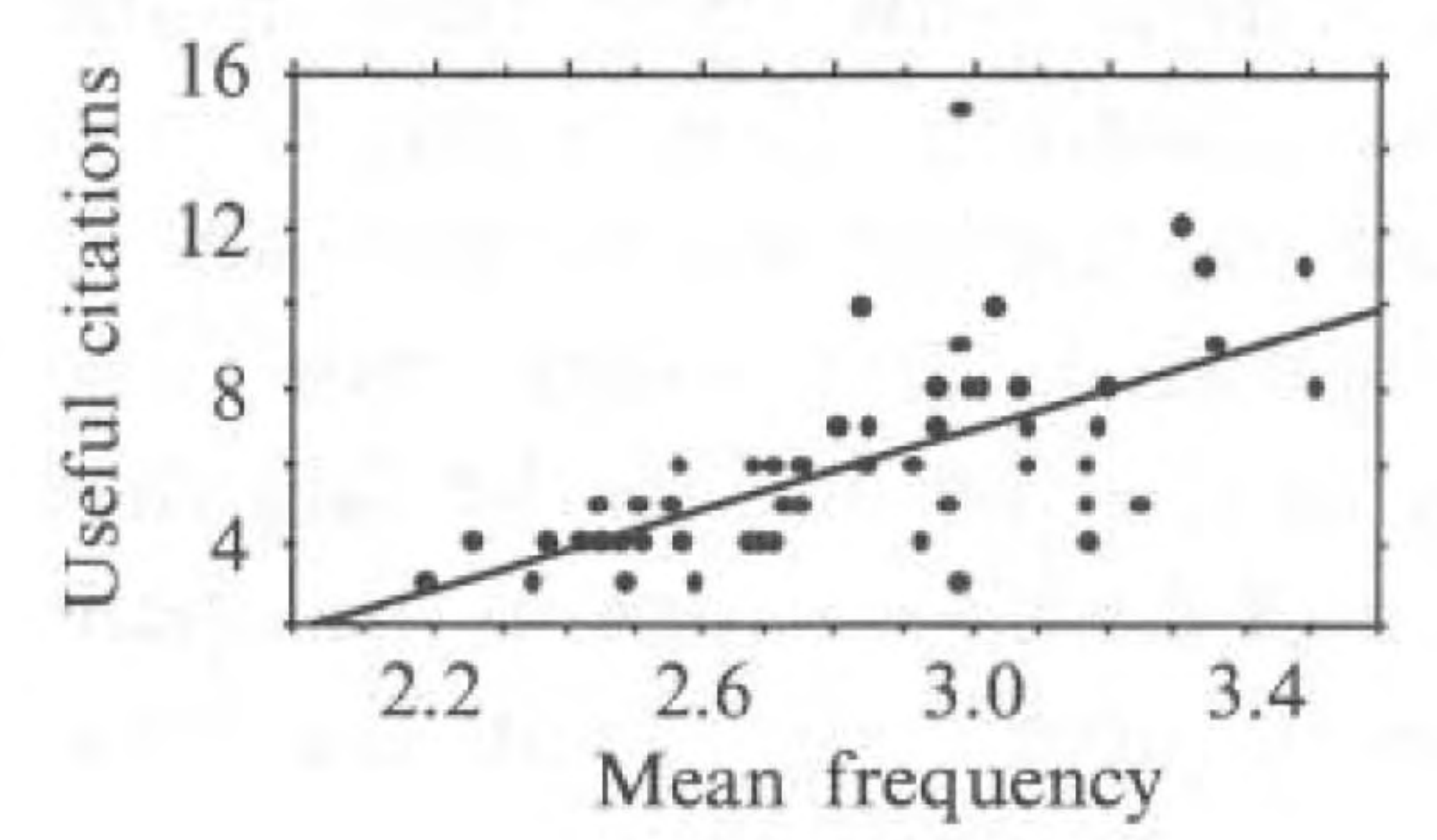

Figure 21. The total of 'useful' citations by those that do not work directly with a person and the mean frequency of being seen for all those who do not have 'whole organisation' jobs, $r=0.630$, $p=0.0001$.

It is obviously important to exclude those people with jobs that bring them into programmed contact with the whole organisation (such as IT support).

The frequency with which a person is seen and his or her usefulness, especially to those who do not normally work with them, is more difficult to link precisely to the individual desk location. The problem is that although people have a desk location they spend between $50 \%$ and $70 \%$ of their time elsewhere. For this reason the location of the workstation does not necessarily provide a good description of the way the spatial pattern of the building makes a person available to others. Availability, and the frequency of contact that seems logically to follow from this, depends on more systematic properties of building pattern in that people are available ast they move around, and this pattern of movement has been shown to depend on the pattern of axial integration.

It is also possible that those in less strategic locations get up and move around to overcome their segregation, more than those whose location brings people and contact past them. This has been found in previous studies and the figures for desk utilisation and visitation ratios (tables 2 and 3) suggest that it is taking place here.

It is probably for these reasons that the relationship of usefulness for those who do not work with someone is linked to the spatial structure of the building at the level of zones and not desks. The four zones considered for this measure were the fourth floor alone, the left-hand side, the top, and the right-hand side of the horseshoe on the fifth floor. From the scatter in figure 22 we can see that the average usefulness of someone to those who do not work with him or her is related to the average spatial integration of the zone in which that person is situated. The most

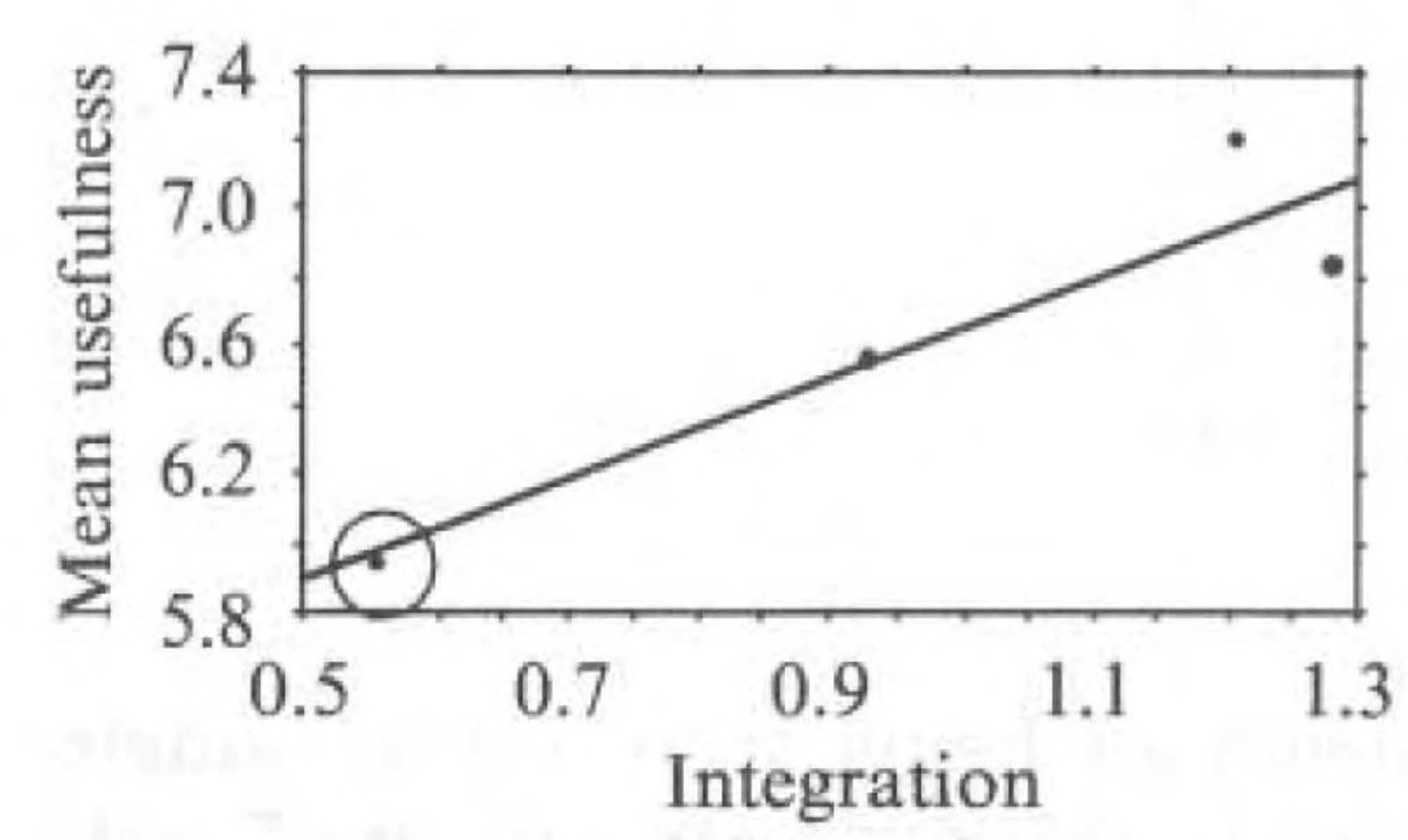

Figure 22. Mean usefulness of people in the four zones of the building and the mean integration of those zones, $r=0.928, p=0.721$. 
integrated zone is the right-hand side, the second is the top, the third is the left, and the fourth floor the least. The higher the mean integration the more useful the people, except for the top two areas where the top of the horseshoe actually outperforms the right-hand side. Because there are only four points on the scatter, the trend is indicative though not statistically significant.

\section{The spatial culture of company $Y$}

The observations of space use, movement, and interaction suggest that company $\mathrm{Y}$ is characterised by a series of robust patterns of behaviour. These are particularly clear on the fifth floor where the space layout of the office is well suited to the dominant patterns of space use and behaviour. The main regularities are as follows. Concentrated individual activity - sitting, reading, and writing, or working at the computer - takes place near the external wall. Movement is concentrated in the horseshoe circulation space that follows the 'curved walls' and then filters off from there into the depths of the work areas. Standing people are concentrated just off the main lines of movement.

It seems that movement gives rise to standing static space use, but that for preference people do not stand where they will get trampled underfoot. Interaction-groups of people in conversation-takes place in one of two characteristic forms, either through programmed meetings in meeting spaces, or through more opportunistic meetings within the open-plan area, or in the offices of creatives.

Spatial analysis of the layout and statistical analysis of the observation data show that patterns of movement are produced by space patterns. Specifically, the degree to which a space is deep or shallow from all other spaces in the office determines the level of movement through that space. Shallower or more 'integrated' spaces carry greater levels of movement than deeper 'segregated' spaces. There is also a direct, though less powerful, effect of depth from the entrance on patterns of movement. As one moves away from the entrance, levels of movement fall off. On the fifth floor, the entrance from the stairs arrives in the integrated corridor and so both in-to-out movement and movement around the floor tend to use space in a similar waty.

The effect of spatial pattern in constructing predominant movement patterns, coupled to the location of workstations with respect to those movement spaces, can be shown to result in a pattern of spatial location of interaction. This pattern is characterised by a split into two types of relationship between movement and talking. Interaction either takes place in the presence of movement and to a degree related to the amount of movement, indicating that it results as a by product of movement, or it takes place in the absence of movement. The former comprises the unprogrammed or opportunistic interaction within and just off the main circulation spaces. The latter are the programmed meetings within cellular office and meeting rooms. Programmed interaction eliminates random contacts and within programmed meeting spaces one is only aware of the people one is meeting with.

So far as interaction is concerned, the open-plan work areas vary in their behaviour. Workstation areas near the circulation core behave most opportunistically and one is aware of a far greater number of people than those in your immediate space. The workstation bays near the external wall somewhat reduce your awareness of people.

These differences seem to be bound into the way that people behave. Video analysis carried out by Budgen (1995) shows that there is a consistent pattern of behaviours in these open-plan areas (figure 23, see over). In general, people who are moving behave in one of two ways. They either walk through 'looking straight ahead' indicating that they are not available or they turn to look at the general work areas as they pass indicating availability for conversation. Similarly, those working at their desks either 'keep their heads down' indicating that they do not want to be disturbed or they look 
Company $\mathrm{Y}$ : video analysis

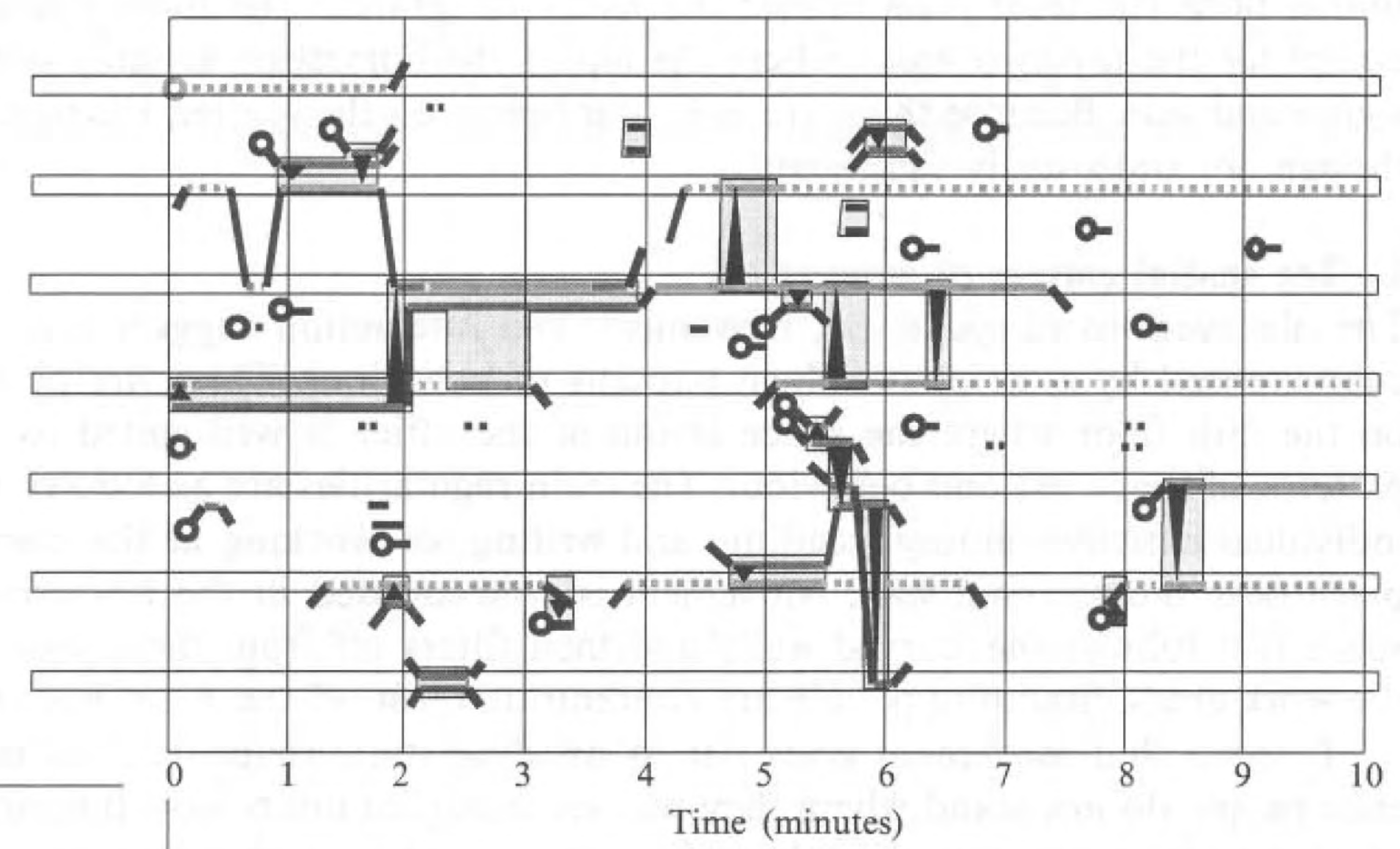

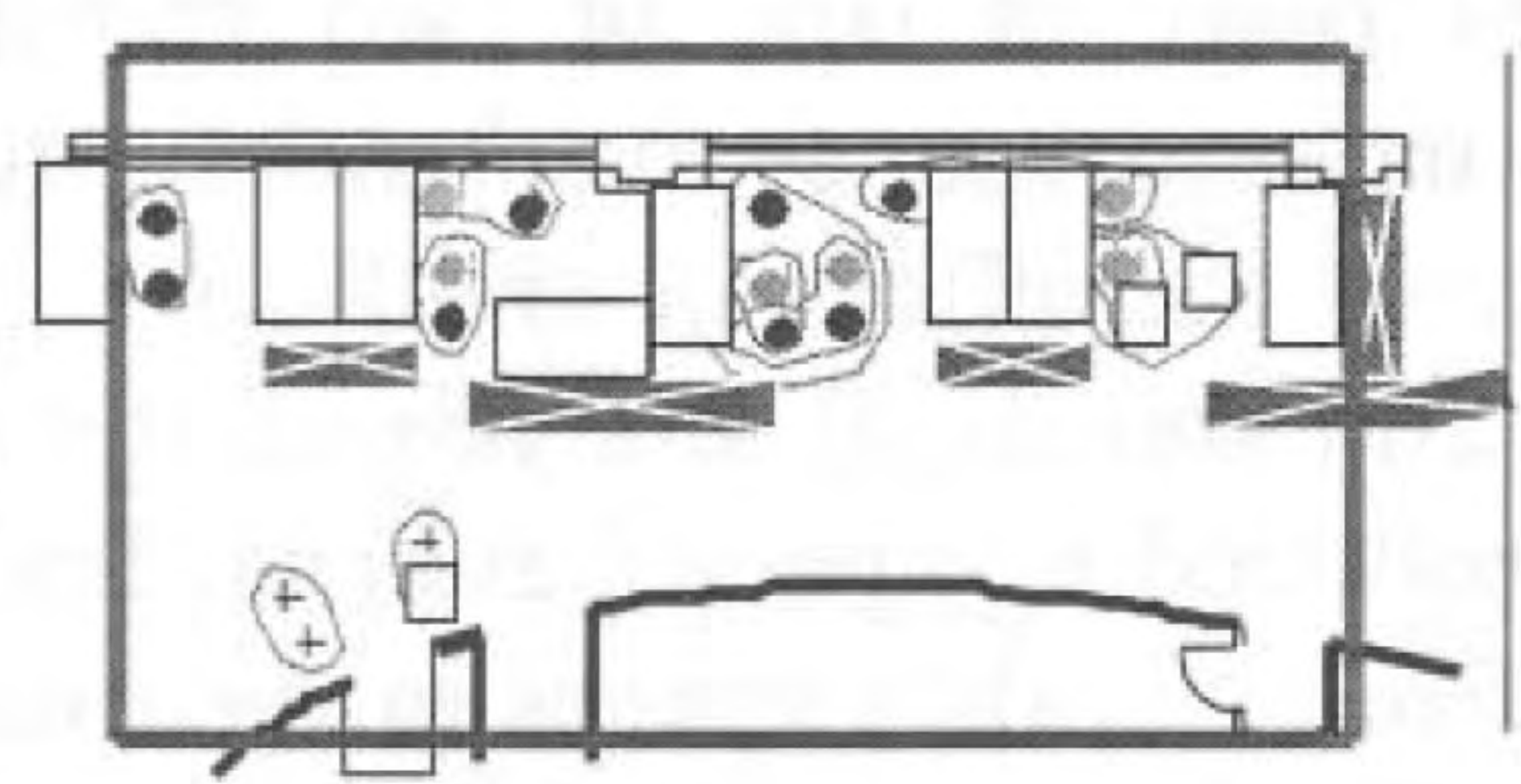

Five-minute interaction maps

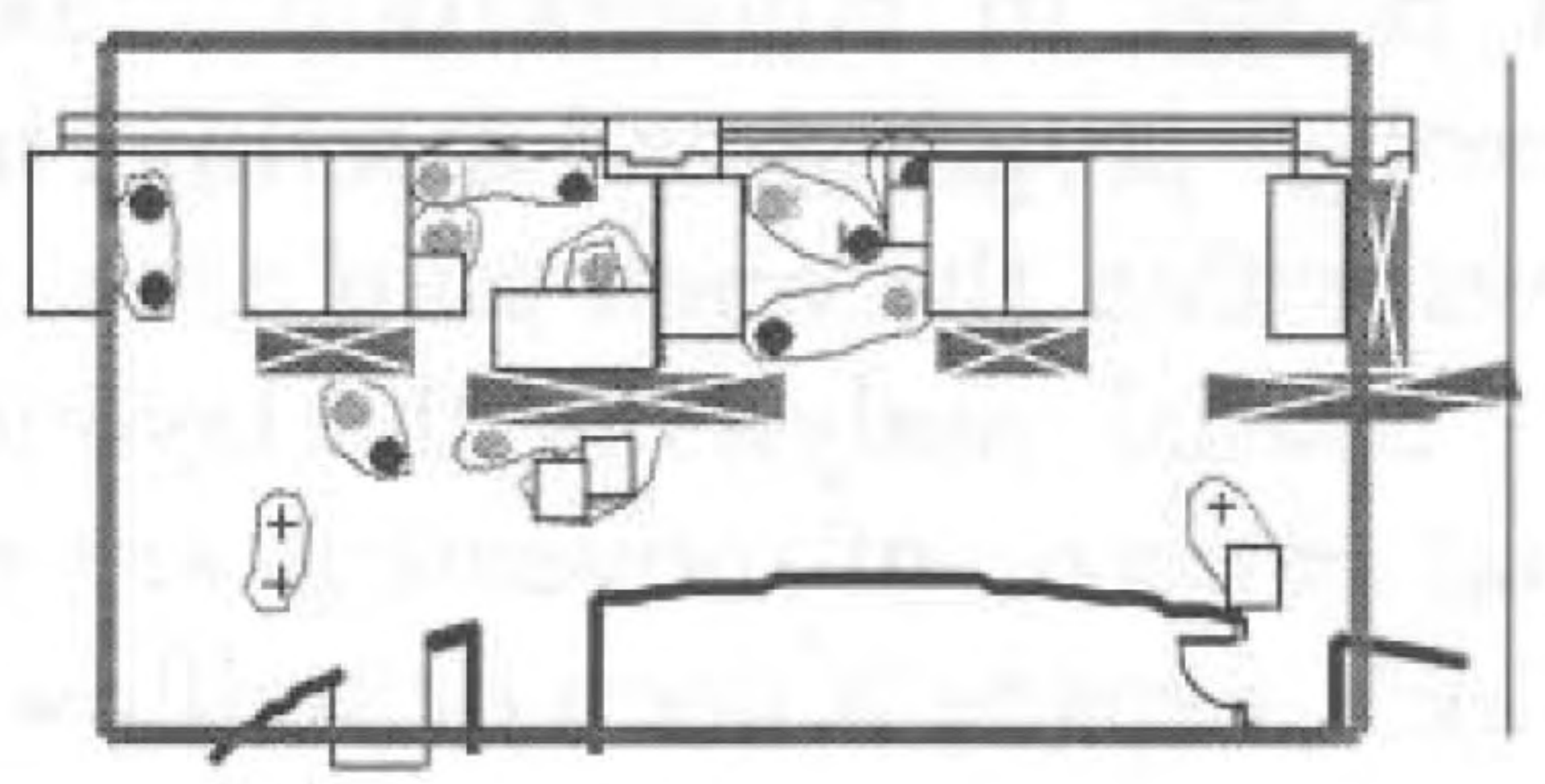

Five-minute interaction maps

\footnotetext{
- sitting and available

... sitting and unavailable

- standing and available

... standing and unavailable

- moving and available

... moving and unavailable

- male (otherwise female)

- recruiter

$\square$ interaction between recruiter and recruited
}

Figure 23. Time-series coding from video of recruitment into interaction in a part of the fifth floor of company Y. The coding shows all moving and static occupancy, including availability. Interactions are hatched and an arrow identifies the recruited person (Budgen, 1995).

up as people pass indicating availability. Two types of interaction follow from this. Where a seated person is the end destination for the moving person (that is, interaction with that person was the reason for them moving) a conversation is initiated irrespective of the microbehaviours of either person. These are planned interactions, at least on the moving person's part. However, there are also a large class of 'unplanned' interactions which are struck up between two people both of whom indicate that they are available for interaction through their microbehaviour. These sometimes involve two movers, or a moving person and a seated person or two seated people in the same area. The key point is that neither the mover nor the seated person knows in advance that the other person will be available, and so the specific conversation is essentially unplanned and unplannable. Unplanned interactions are the most frequent form of interaction that can be observed in the open-plan areas and constitute $70 \%$ of all unprogrammed interaction, with planned interaction making up the remaining $30 \%$. The duration of these 
interactions is generally short with over $70 \%$ of conversations lasting less than 30 seconds and over $90 \%$ lasting less than two minutes.

It seems likely, though we cannot supply data in support of this, that planned interaction dominates in the peripheral areas of the open plan, and unplanned interaction predominates in the central areas. In this sense it seems that the disposition of the open-plan general work area may serve to structure the probabilities of unplanned interactions, whereas the cellular office and meeting room areas tend to eliminate precisely this element of interaction. We could say that so far as the organisation is concerned the spatial structure of the fifth floor constructs and controls interfaces between people in this way.

Whereas the layout of the fifth floor reinforces this natural pattern of interface construction, on the fourth floor the layout runs counter to it in a number of ways. First, the entrance is removed from the most integrated space within the floor on its own. Second, there is a back corridor between the desks and the exterior wall which gains a fair degree of movement within the office. Third, the main programmatic functions and attractors, the meeting rooms, photocopier, and kitchen all link to a short cross route that links both back and front corridors through the photocopier area, and this is the most locally integrating route on the floor whilst it is removed from the entrance. Lastly, the silver screen wall that separates the general open-plan area from the front corridor places a barrier between open-plan work and most of the in-to-out movement on the floor, much of which uses the front corridor to get to meeting rooms or offices at either end of the floor.

The effect of these moves is striking. Whereas a relatively natural and unforced interface is built up on the fifth floor between movement, standing, and seated interaction, and those coming in and out of the floor are brought directly into contact with it, on the fourth floor the interface is almost entirely eliminated. The higher the levels of movement a space has, the lower the levels of interaction. Essentially, the fourth floor breaks the relationship between passers-by and those sitting down so that opportunistic interaction is strongly controlled. This makes the floor behave much more like a programmed meeting space in which only planned interaction is likely to take place.

The effect is symbolised-as well as partly constructed-through the use of the silver screen wall to separate movement from general open-plan work areas, in opposition to its counterpart on the fifth floor-the red curved wall-which is used to separate programmed meeting spaces from the remainder.

Although these effects are clearly observable, and tell us a lot about the perceived differences between the two floors, it is not clear that interaction is necessarily important for people's work. However, the findings of the communication questionnaire survey suggested that space did play an important role, because the more frequently a person is seen the more people find him or her useful in their work. This pattern holds for the organisation overall and repeats for all the different categories of people-creatives, founder partners, associated in-house companies - but with varying degrees of usefulness for a given frequency of being seen. For instance, a founding partner is generally considered more useful for a given frequency of being seen than other people, and 'spinoff' company personnel are considered slightly less useful. Certain key individuals with functions which support the whole organisation (IT and finance, for example) are found significantly more useful than their frequency of being seen would suggest. For most staff on single accounts who do not have this 'whole organisation' role or status, the link between frequency and usefulness is direct and strong. Even when we exclude those who work directly with someone from the citation score we find that frequency of being seen is the key criterion affecting their usefulness. 
The effects of the spatial layout of $\mathrm{K}$ house on the usefulness of staff to each other are best measured in terms of building segments. If we take the average level of usefulness of people who work in each of the three legs of the fifth floor horseshoe and the fourth floor, excluding those with whole organisation functions, we find a direct correlation between this and the mean degree of integration of the segment of the building. This suggests that the effects of the relative segregation of the fourth floor are detectable at the level of the perceived usefulness of its occupants.

How important this is to company $\mathrm{Y}$ is open to question. When we look at the average usefulness of all staff to those that do not work directly with them, and the mean degree of integration of the building as a whole, we find that company $Y$ performs exactly as would be predicted on the basis of the previous studies of research laboratories. Figure 24 shows the same scattergram as figure 1 with company $Y$ inserted. However, the degree of spatial integration that is possible within the shell and core configuration of $\mathrm{K}$ house is being exploited to the maximum on the fifth floor already. There is little that could be done to improve it. This suggests that there is little that could be done with spatial means to improve the degree of interaction and useful communication within the existing building. However, it is clear from the laboratory studies that organisations with more integrated spatial layouts can achieve significantly higher degrees of useful work-related communication. Company $\mathrm{Y}$ is about halfway up the league of organisations we have studied, both in terms of the spatial integration of $\mathrm{K}$ house and in terms of the outcome of this in useful interaction. There seems to be considerable room for improvement but not within the constraints of shell and core imposed by $\mathrm{K}$ house. These last comparative results need to be considered with a fair degree of wariness. All previous work in which these methods were used has been carried out in scientific research laboratories which have quite different working practices and cultures. It was by no means clear that company $Y$ would fit into the same model. However, we believe that a more general theoretical understanding of the relationship between work environments and innovative organisations can be constructed.

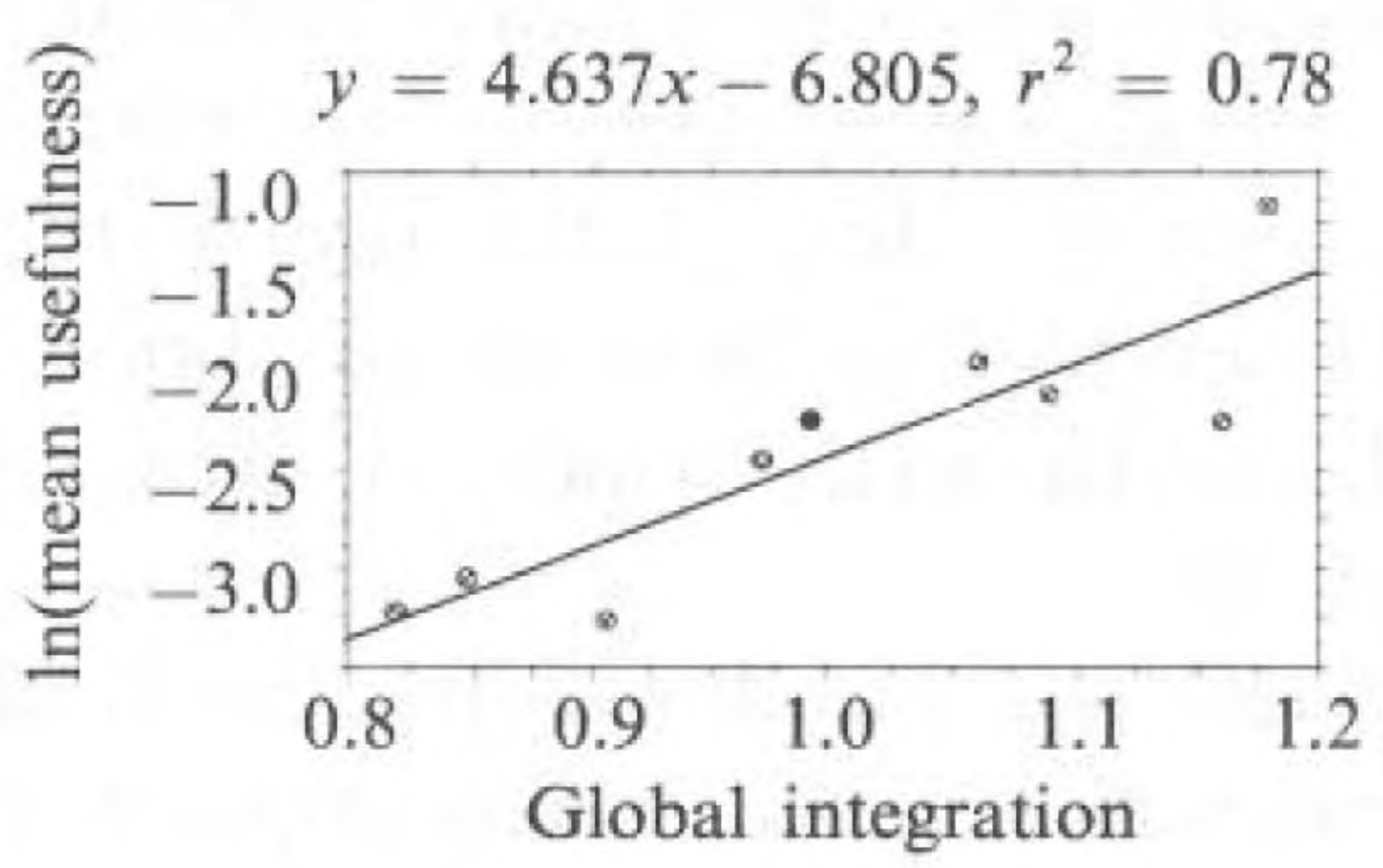

Figure 24. The natural logarithm of mean usefulness of staff outside their work group for company $\mathrm{Y}$ and the mean integration of the offices of $\mathrm{K}$ house plotted as a solid dot on a scatter with eight research laboratory organisations studied by using the same methods, $r=0.883$, $p=0.001$.

An organisation such as company Y places a high priority on innovation. This is a matter of innovation both in ideas - the traditional role of creatives - and in social forms, such as team formation, fixing meetings, and just 'getting things done'. However, not all work is interactive between people. No matter how good the ideas that emerge from group discussions are, at some point they have to be turned into a real product-visuals and words - so that they can be shared between people. This work can be much more personal-entailing a dialogue between people and things (pen and paper or computer), or bringing into contact people with ideas and those with craft skills. These different forms of activity need to be provided for by the spatial resources of the building. At one level, unplanned interaction provides the main resource for rapid 
transfer of ideas and formation of flexible working groups. This depends on shallowness and access and the interface between movement and general work. At the opposite extreme, when it comes to execution of a set of tasks, programmed meetings and individual work both require the reduction of interruptions to a minimum. Most classes of job need both types of spatial resource, at different times and in different measures. At present the only people who have access to both are the creatives who have seclusion when they need it and can get up and walk around the office if they feel in need of interaction and stimulation. Traditional open-plan organisations tend to be organised in this way with privileged access to spatial differentiation granted to higher status individuals and functions, and with lower statuses allocated to relatively undifferentiated space.

\section{The nomad in the office landscape}

As a part of the exercise in which this study was involved, company Y decided to carry out an experiment in flexible allocation of workspace amongst its staff. Staff volunteered to give up their individual desk locations in order to become 'rompers' ('romp' stands for Real Office Mobility Project). In place of individual allocated desks, rompers could choose from a wide range of different work locations in various parts of the building, offering different degrees of isolation or integration and different types of environment-light, dark, quiet, noisy, large, and small. The effect of the romping changes was to increase greatly the spatial differentiation of the general work areas in the plan, providing several much more segregated areas on both the fifth and the fourth floors, but allowing equal access to all these spaces to all rompers. The romping exercise has yet to be fully evaluated. However, early responses from the staff involved are very positive.

An important question that arises from this experiment is whether it is possible to couple a higher degree of spatial differentiation in the open-plan general work areasproviding for privacy and community - with the removal of individual rights to desk locations, in such a way as to give everyone privacy when their job dictates and the option to move to more public space when that seems desirable. The concern is that the result of spatial differentiation will be to fossilise particular structures as these emerge in the organisation, through a process in which those who have the most power (either through status or need) secure privileged access to space. It may be that the six-monthly move strategy is possible only in general office areas where there is relatively little spatial differentiation between different desk locations. If there were a greater degree of differentiation in these spaces then it is possible that more fixed statuses might emerge to argue for privileged rights to space. This is effectively the current situation for creatives.

There seem to be two possibilities. If differentiation is invested in group spaces to which all have equal access - the cafe or library, for instance - then it is possible that fossilisation of individual roles or statuses would not take place. We might think of differentiation at this level as global differentiation. The question that follows is whether local differentiation within a group work space-say an open-plan office area-can work or whether it would lead to fossilisation. There seem to be certain preconditions. If 'hot desks' are proposed for everyone, then the rules on clearing desks each evening would need to be very strong, as would strategies for storing 'things', if individuals are not to gain rights over space. Similarly, it would seem necessary not only to provide for the spatial and environmental needs of different tasks and activities, but also to provide for their different temporal needs. Some activities last a minute, others an hour, others a day or a week or a month. It is likely that some degree of redundancy would be needed in provision of different classes of space so that different timescales of use could also be accommodated. Again, strict enforcement of timekeeping would be necessary if 'squatting' is to be avoided. 
However, the real implications of this type of strategy are more thoroughgoing. Effectively, the removal of rights of individuals to space makes everyone a visitor to the building, much as students are in a campus or pedestrians are in the city. In this situation it is possible for 'hidden' power structures to emerge (the bully in the school playground is one example) that can be far more conservative in their effects than the more explicit power structures embodied in organisationally sanctioned statuses. If these power structures are to be avoided, then mechanisms will need to be developed to control their emergence. It seems likely that an apparent 'freeing up' of access to spatial differentiation for all categories of staff will entail a reciprocal 'tightening up' of codes of behaviour and especially those governing space use. As the utilisation of space becomes temporary and the office society becomes effectively 'nomadic', rule systems surrounding space use and cultural devices to allow individuals and groups to maintain their identity are both likely to become more elaborate. In company $\mathrm{X}$ we saw the effects of spatial integration and visual openness manifest themselves in a degree of reinforcement of the group identity through manipulation of the spatial layout, but it remains to be seen what form the elaborated rule systems will take in company Y.

\section{References}

Allen T, 1977 Managing the Flow of Technology (MIT Press, Cambridge, MA)

Backhouse A, Drew P, 1992, "The design implications of social interaction in a workplace setting" Environment and Planning B: Planning and Design $19573-584$

Beer S, 1966 Decision and Control (John Wiley, Chichester, Sussex)

Budgen A, 1995, "Breaking boundaries: the sole of space in process and product innovation", MSc thesis, The Bartlett School of Graduate Studies, UCL, London

Grajewski T, 1992 Interaction in the Work Environment $\mathrm{PhD}$ Thesis, The Bartlett School of Graduate Studies, UCL, London

Hillier B, Grajewski T, 1987, "The application of space syntax to work environments inside buildings", final report (Unit for Architectural Studies, UCL, London)

Hillier B, Penn A, 1991, "Visible colleges: structure and randomness in the place of discovery" Science in Context $423-49$

Hillier B, O’Sullivan P, Penn A, Kolokotroni M, Rasmussen M, Xu J, Young A, 1990, “The design of research laboratories", report to the Steering Committee of the Laboratories Investigation Unit of the DES (Unit for the Architectural Studies, UCL, London)

Penn A, Hillier B, 1992, "The social potential of buildings: space and the innovative milieu in scientific research laboratories", in Proceedings of the Corporate Space and Architecture Conference; reprinted in French translation as "Structure spatiale et innovation dans les laboratoires de recherche scientifique: le potential social des bâtiments", in De L'Atelier au Territoire: Le Travail en quête D'Espaces Eds T Evette, F Lautier (L'Harmattan, Paris) pp $215-224$

Shanks M, 1967 The Innovators: The Economics of Technology (Penguin Books, Harmondsworth, Middx) 